\title{
Roles of cellular senescence in driving bone marrow adiposity in radiation- and aging-associated bone loss
}

Abbreviated title: Senescence regulates bone marrow adiposity

Authors: Abhishek Chandra ${ }^{1,2,3^{*}}$, Anthony B. Lagnado ${ }^{1,3}$, Joshua N. Farr ${ }^{1,3,4}$, Megan Schleusner $^{3}$, David G. Monroe $^{3,4}$, Christine Hachfeld ${ }^{3}$, João F. Passos ${ }^{1,2,3}$, Sundeep Khosla ${ }^{3,4}$, Robert J. Pignolo ${ }^{1,2,3,4^{*}}$

${ }^{1}$ Department of Physiology and Biomedical Engineering, ${ }^{2}$ Department of Medicine, ${ }^{3}$ Robert and Arlene Kogod Center on Aging, ${ }^{4}$ Division of Endocrinology, Mayo Clinic College of Medicine, Rochester, Minnesota, USA

Funding: The work was supported by Eagle's Cancer Research Fund (to AC), Mayo Clinic Clinical and Translational Science Award (CTSA), grant number UL1TR002377, from the National Center for Advancing Translational Science (NCATS), a component of the National Institutes of Health (NIH) (to AC) and UL1TR000135, Center for Clinical and Translation Science (CCATS)(to DGM and AC), as well as the Robert and Arlene Kogod Professorship (to RJP); P01 AG062413 (SK, JNF, RJP), P01 AG004875 (SK/DGM), R01 AG048792 (SK/DGM), R01 AR068275 (DGM), and, R01 DK128552 (JNF), and K01 AR070241 (JNF).

Emails:

- Abhishek Chandra: chandra.abhishek1@mayo.edu; ORCiD: 0000-0001-9423-9669

- Anthony B. Lagnado: lagnado.anthony@mayo.edu; ORCiD: 0000-0002-9380-5179

- Joshua N. Farr: farr.joshua@mayo.edu; ORCiD: 0000-0002-3179-6414

- Megan Schleusner: schleusner.megan@mayo.edu

- David G. Monroe: monroe.david@mayo.edu; ORCiD: 0000-0002-4818-0114

- Christine Hachfeld: hachfeld.christine@mayo.edu

- João F. Passos: passos.joao@mayo.edu; ORCiD: 0000-0001-8765-1890

- Sundeep Khosla: khosla.sundeep@mayo.edu; ORCiD: 0000-0002-2936-4372

- Robert J. Pignolo: pignolo.robert@mayo.edu; ORCiD: 0000-0002-8533-9438

\section{*Corresponding authors:}

*Abhishek Chandra, M.Sc. Ph. D., Guggenheim 7, Mayo Clinic College of Medicine, 200 First Street SW, Rochester, MN 55905; Tel.+1-507-266-1847; Email: chandra.abhishek1@mayo.edu

*Robert J. Pignolo, M.D. Ph. D., Guggenheim 7, Mayo Clinic College of Medicine, 200 First Street SW, Rochester, MN 55905; Tel: +507-293-0813; Email: pignolo.robert@mayo.edu

Key Words: aging, radiation, senescence, bone, bone marrow adiposity

Supplementary material: This manuscript contains Supplementary Information, Figures, and Tables

Disclosure: The authors have declared that no conflict of interest exists. 
Osteoporosis is associated with an increase in marrow adipocytes, collectively termed bone marrow adipose tissue (BMAT). An increase in BMAT is linked with decline of mesenchymal progenitors that give rise to osteoblasts which are responsible for bone accrual. Oxidative stress-induced reactive oxygen species, DNA damage, apoptosis and cellular senescence have been associated with reduced osteoprogenitors in a reciprocal fashion to BMAT; however, a direct (causal) link between cellular senescence and BMAT is still elusive. Accumulation of senescent cells occur in naturally aged and in focally radiated bone tissue, but despite amelioration of age- and radiation-associated bone loss after senescent cell clearance, molecular

57 events that precede BMAT accrual are largely unknown. Using a mouse model here we show by RNA-

58 Sequencing data that BMAT-related genes were the most upregulated gene subset in radiated bones. Using focal radiation as a model to understand age-associated changes in bone, we performed a longitudinal assessment of cellular senescence and BMAT. Using qRT-PCR, RNA in situ hybridization and histological assessment of telomere dysfunction as a marker of senescence, we observed increased $p 21$ transcripts in bone lining cells, osteocytes and bone marrow cells, and elevated dysfunctional telomeres in osteocytes starting from day 1 post-radiation, without the presence of BMAT. BMAT was significantly elevated in radiated bones at day 7, confirming the qRT-PCR data in which most BMAT-related genes were elevated by day 7 , and the trend continued until day 42 post-radiation. Similarly, elevation in BMAT-related genes was observed in aged bones. The senolytic cocktail of Dasatinib (D) plus Quercetin (Q) - D+Q, which clears senescent cells, reduced BMAT in aged and radiated bones. MicroRNAs (miRs) linked with senescence marker $p 21$ were downregulated in radiated- and aged- bones, while miR-27a, a miR that is associated with increased BMAT, was elevated both in radiated- and aged-bones. D+Q downregulated miR27a in radiated bones at 42 days post-radiation. Overall, our study provides evidence that BMAT occurrence

71 in oxidatively stressed bone environments, such as radiation and aging, is induced following a common 72 pathway and is dependent on the presence of senescent cells. 


\section{Introduction}

77 Mechanisms underlying bone deterioration during physiological and pathological conditions have been a

78 focus of study for many years. The balance between bone forming osteoblasts and bone resorbing

79 osteoclasts maintains normal bone coupling and marked deviation from this well-orchestrated mechanism

80 causes either osteoporosis (due to comparatively more osteoclast function) or osteopetrosis (due to

81 relatively increased bone formation with no or minimal bone resorption)(Abhishek Chandra, Rosenzweig,

82 \& Pignolo, 2018). In common physiological conditions, such as aging or post-menopausal status,

83 osteoporosis is the more prevalent condition and also associated with increased marrow fat or bone marrow

84 adipose tissue (BMAT)(Veldhuis-Vlug \& Rosen, 2018). BMAT in humans has been shown throughout the

85 lifespan with no potential side effects on bone architecture up to a certain age; but with aging, disease and

86 post-menopausal status, the presence of marrow fat appears to be inversely proportional to bone mass

87 (Devlin \& Rosen, 2015). BMAT has also been used as a predictor of bone loss showing a direct correlation

88 to osteoporosis(Woods et al., 2020).

An increase in BMAT has been associated with depleted resident mesenchymal stem cells (MSCs) during aging and disease, as MSCs are a common precursor to both adipocytes and osteoblasts. In fact, with aging MSCs undergo linage switching toward an adipogenic fate (A. Chandra et al., 2017; Singh et al., 2016; Zhong et al., 2020). Only recently is it better understood that marrow fat cells have an autocrine, paracrine and endocrine function, with local and systemic effects(Suchacki \& Cawthorn, 2018). In observations made by multiple studies, bone resorption and BMAT are directly related, but adipocyte-secreted factors that regulate bone resorption or those that potentially affect bone formation are still unknown.

96 Cellular senescence is a non-proliferative, biologically active state (Hayflick, 1965) that produces an active 97 secretome known as the senescence-associated secretory phenotype (SASP)(Coppe, Desprez, Krtolica, \& 98 Campisi, 2010). Cellular senescence is one of the key underlying mechanisms accounting for age- and 99 radiation-related bone deterioration (A. Chandra et al., 2020b; Farr et al., 2016; Farr et al., 2017). In bone 100 tissue, senescence and SASP have been reported in osteoblasts, osteocytes, osteoprogenitors and myeloid 101 cells, with senescent myeloid cells and osteocytes being the major contributors to the SASP(Farr et al., 
102

103

104

105

106

107

108

109

110

111

112

113

114

115

116

117

118

119

120

121

122

123

124

125

126

127

2016). We have shown that BMAT is correlated with the presence of DNA damage, and mitigation of DNA damage can reduce BMAT and improve bone architecture post-radiation (A. Chandra et al., 2017; A. Chandra et al., 2018). We have also shown that focal radiation emulates several age-associated phenotypes (A. Chandra, Park, \& Pignolo, 2019) with an increase in markers of senescence and SASP in bone marrow cells, osteoblasts and osteocytes (A. Chandra et al., 2020b). Interestingly, we have shown that $p 21$ expression was more robust at earlier time-points post-radiation than $p 16^{\operatorname{Ink} 4 a}$, while $p 16^{\operatorname{Ink} 4 a}$ peaked much later (A. Chandra et al., 2020b). We have previously observed a reduction in BMAT following clearance of senescent cells in aged- and radiated- bones (A. Chandra et al., 2020a; Farr et al., 2017).

However, a comprehensive molecular comparison between radiation-induced BMAT and aging-induced BMAT has not yet been described.

The spectrum of adipokines that increase with cellular senescence and have the potential to cause detrimental systemic effects, are still unknown. To understand the triggers for accumulation of BMAT during aging and potential adipokine-associated genes, we used a radiation model to perform a longitudinal gene expression analysis of BMAT-related genes and compared them with those of bone tissue from old mice. We also explored the sequence of events early after radiation, to understand whether senescence precedes the accumulation of BMAT. Finally, we describe the relationships among BMAT, microRNAs (miRs) that regulate adiposity, and cellular senescence in in vivo models of focal radiation to bone, agerelated bone loss, and pharmacologic clearance of senescent cells.

\section{Results}

\subsection{Gene expression of adipocyte related genes in radiated bones}

RNA isolated from a focally radiated $5 \mathrm{~mm}$ area of the femoral metaphysis 3 weeks post-radiation was processed for RNA sequencing. Identified genes were then arranged based on their- $\log 10$ (False Discovery

Rate). The genes with the highest - $\log 10$ (False Discovery Rate) value when depicted using a volcano plot showed that the senescence marker Cdkn1a (p21) and several adiposity related genes (Cidec, Plin1, Plin4, $L p l$, Igf2) were among the most upregulated genes, while genes that were associated with endothelial function (Vwf4, Ppbp, Pf4 and Mmrn1) were among the most downregulated (Fig.1A). 
$\mathbf{A}$

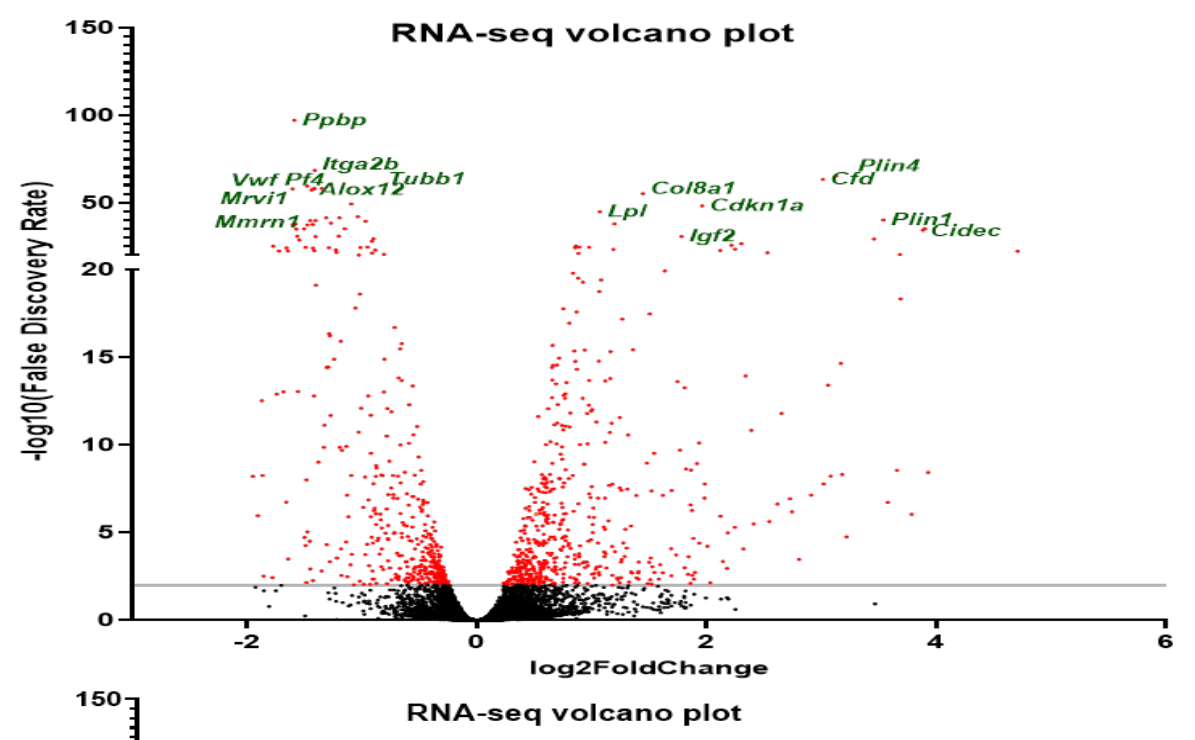

$\mathbf{B}$

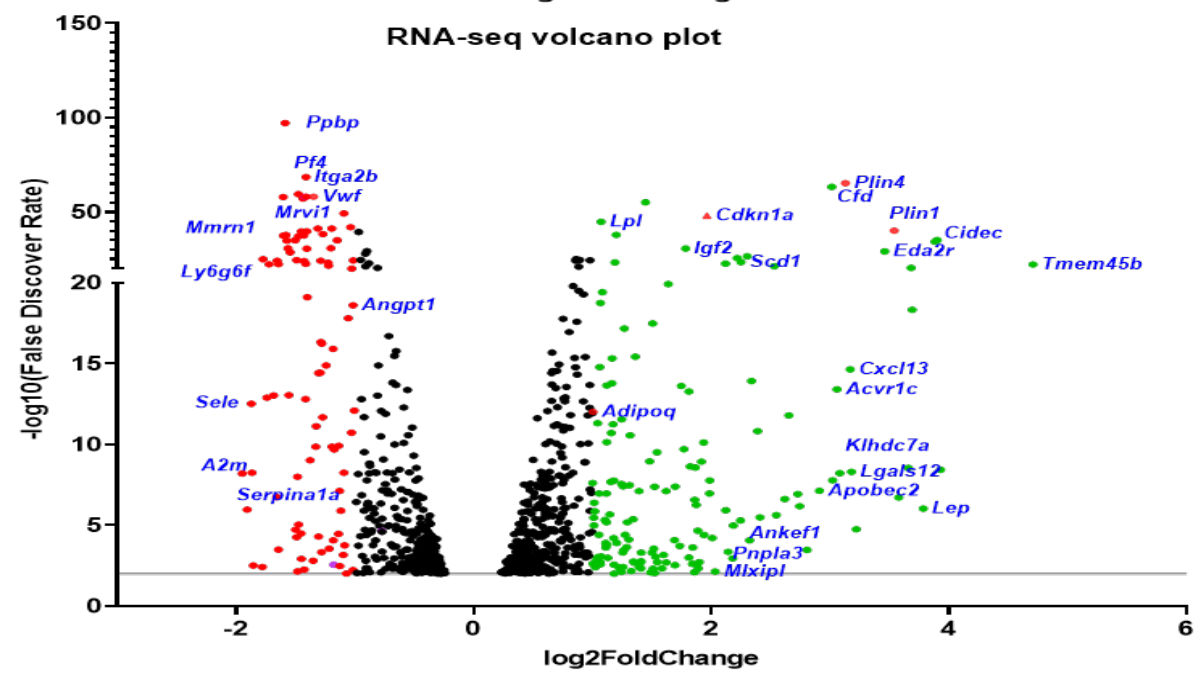

Figure 1. Volcano plot of the transcriptome in the radiated bones

(A) The right femoral metaphyses of C57BL/6 mice $(\mathrm{n}=3)$ were radiated (24Gy) in a $5 \mathrm{~mm}$ region, while the equivalent region of the left leg served as control. R- and NR-femurs at day 21 post-radiation were harvested for mRNA isolation. Volcano plots were generated to present the RNA-Seq data. Volcano plots of differentially expressed genes were generated from two-tailed Student's t-test. The horizontal line and vertical lines indicate the significance threshold (FDR $<0.05)$ and two-fold change threshold $(\mid \log 2$ FoldChange $\mid>1)$, respectively. The differentially expressed genes (DEGs) are shown with red dots while nonDEGs are in black. (B) Upregulated DEGs with a log2Fold Change of 1 or more in the radiated bones are depicted with greencolored spots and downregulated DEGs with a log2Fold Change of 1 or more are depicted with red-colored spots. Black dots indicate all significant changes in the DEGs.

128 When the genes were plotted using fold-change, we observed the same trend, and several more genes related

129 to adipocyte function were sorted into the top 50 most up-regulated genes (Fig.1B).

Within the gene set significantly expressed in our RNA sequencing data (1405 genes), we next curated a

list of genes that play a role during adipocyte differentiation in different cell types (Table 1). Based on this curated list, we generated a heat map (Fig.2A) which showed that most of these genes were elevated in the 
bioRxiv preprint doi: https://doi.org/10.1101/2021.09.07.459232; this version posted September 8,2021 . The copyright holder for this preprint (which was not certified by peer review) is the author/funder, who has granted bioRxiv a license to display the preprint in perpetuity. It is made available under aCC-BY 4.0 International license.

134 (Fig.2B) we used qRT-PCR to further confirm the expression of the selected genes during adipocyte

135 differentiation of human MSCs (Supp. Fig.1).

Table 1. List of genes related to adipocyte function

\begin{tabular}{llll}
\hline Gene Name & Description & Signal type (Reference)
\end{tabular}

5.0

\begin{tabular}{|c|c|c|c|}
\hline Adipoq & Adiponectin & Yes & \multirow{13}{*}{$\begin{array}{l}\text { Human-adipose derived stem cells (ASC) (Ambele, } \\
\text { Dessels, Durandt, \& Pepper, 2016) }\end{array}$} \\
\hline Cidec & $\begin{array}{l}\text { Cell death-inducing } \\
\text { DFFA-like effector c }\end{array}$ & No & \\
\hline Plin1 & Perilipin 1 & No & \\
\hline Gpd1 & $\begin{array}{l}\text { Glycerol-3-phosphate } \\
\text { dehydrogenase } 1\end{array}$ & No & \\
\hline Mlxipl & $\begin{array}{l}\text { MLX interacting protein- } \\
\text { like }\end{array}$ & No & \\
\hline Igfl & Insulin like growth factor 1 & No & \\
\hline Pnpla3 & $\begin{array}{l}\text { Patatin-like phospholipase } \\
\text { domain containing } 3\end{array}$ & No & \\
\hline Tusc5/Trarg1 & $\begin{array}{l}\text { Trafficking regulator of } \\
\text { GLUT4 (SLC2A4) } 1\end{array}$ & No & \\
\hline Aoc3 & $\begin{array}{l}\text { Amine oxidase, copper } \\
\text { containing } 3\end{array}$ & No & \\
\hline Lipe & $\begin{array}{l}\text { Lipase E, hormone } \\
\text { sensitive type }\end{array}$ & No & \\
\hline Mcam & $\begin{array}{l}\text { Cell surface glycoprotein } \\
\text { MUC18 }\end{array}$ & Yes & \\
\hline Glul & Glutamate-ammonia ligase & No & \\
\hline$P d e 3 b$ & Phosphodiesterase 3B & No & \\
\hline Fabp4 & $\begin{array}{l}\text { Fatty Acid Binding Protein } \\
4\end{array}$ & No & $\begin{array}{l}\text { ASC(Ambele et al., 2016), Microarray (Birsoy et al., } \\
\text { 2011) }\end{array}$ \\
\hline Cxcl13 & $\begin{array}{l}\text { Chemokine (C-X-C motif) } \\
\text { ligand } 13\end{array}$ & Yes & $\begin{array}{l}\text { (Kusuyama, Komorizono, Bandow, Ohnishi, \& } \\
\text { Matsuguchi, 2016) }\end{array}$ \\
\hline Plin4 & Perilipin 4 & No & ASC(Ambele et al., 2016), (Secco et al., 2017) \\
\hline Acvrlc & Activin A receptor, type IC & Yes & $\begin{array}{l}\text { 3T3L1, SVF cells(Kogame et al., 2006) Human BM- } \\
\text { MSC(Menssen et al., 2011) }\end{array}$ \\
\hline$C f d$ & $\begin{array}{l}\text { Complement factor } \mathrm{D} / \\
\text { Adipsin }\end{array}$ & Yes & \multirow[t]{2}{*}{$\begin{array}{l}\text { ASC(Ambele et al., 2016), 3T3L1, WAT(Birsoy et } \\
\text { al., 2011) Human BM-MSC(Menssen et al., 2011) }\end{array}$} \\
\hline Pparg & $\begin{array}{lr}\text { Peroxisome } & \text { Proliferator } \\
\text { Activated } & \text { Receptor } \\
\text { Gamma } & \\
\end{array}$ & No & \\
\hline Atpla2 & $\begin{array}{l}\text { ATPase, } \mathrm{Na}+/ \mathrm{K}+ \\
\text { transporting, alpha } 2\end{array}$ & No & SW872 (Yin et al., 2014) \\
\hline Thrsp & $\begin{array}{l}\text { Thyroid hormone } \\
\text { responsive }\end{array}$ & No & Human adipocytes(Ortega et al., 2010) \\
\hline Lgals12 & Galectin 12 & No & 3T3L1, human adipose tissue(Hotta et al., 2001) \\
\hline $\lg f 2$ & $\begin{array}{l}\text { Insulin-like growth factor } \\
2\end{array}$ & Yes & Rat ADSC(C. Wang et al., 2019) \\
\hline Rbp4 & Retinol binding protein 4 & Yes & \multirow{3}{*}{$\begin{array}{l}\text { human multipotent adipose tissue-derived stem cells } \\
\text { (hMADS)(Scheideler et al., 2008) }\end{array}$} \\
\hline Fabp5 & $\begin{array}{l}\text { Fatty acid binding protein } \\
5\end{array}$ & No & \\
\hline$N r 1 h 3$ & $\begin{array}{l}\text { Oxysterols Receptor LXR- } \\
\text { Alpha }\end{array}$ & No & \\
\hline
\end{tabular}


bioRxiv preprint doi: https://doi org/10.1101/2021.09.07.459232; this version posted September 8,2021 . The copyright holder for this preprint (which was not certified by peer review) is the author/funder, who has granted bioRxiv a license to display the preprint in perpetuity. It is made available under aCC-BY 4.0 International license.

\begin{tabular}{|c|c|c|c|}
\hline Lpl & Lipoprotein lipase & Yes & \multirow{3}{*}{$\begin{array}{l}\text { 3T3L1, White adipose tissue (WAT) (Birsoy et al., } \\
\text { 2011) }\end{array}$} \\
\hline Scd1 & Stearoyl-CoA desaturase 1 & No & \\
\hline Lep & Leptin & Yes & \\
\hline Rarres2 & $\begin{array}{l}\text { Retinoic acid receptor } \\
\text { responder } \\
\text { induced) } 2 \text { (tazarotene } \\
\text { inemerin }\end{array}$ & Yes & 3T3L1(Goralski et al., 2007) \\
\hline Ccdc3 & $\begin{array}{l}\text { Coiled-coil } \\
\text { containing } 3\end{array} \quad$ domain & Yes & $\begin{array}{l}\text { Rat primary adipocytes and adipose tissue(Kobayashi } \\
\text { et al., 2010) }\end{array}$ \\
\hline Col5a3 & $\begin{array}{l}\text { Collagen type V alpha } 3 \\
\text { chain }\end{array}$ & Yes & \multirow[t]{5}{*}{ Human BM-MSC(Menssen et al., 2011) } \\
\hline Igfbp5 & $\begin{array}{l}\text { Insulin like growth factor } \\
\text { binding protein } 5\end{array}$ & Yes & \\
\hline Plin2 & Perilipin 2 & No & \\
\hline$G h r$ & Growth hormone receptor & Yes & \\
\hline Rxra & $\begin{array}{lll}\begin{array}{l}\text { Retinoid } \\
\text { Alpha }\end{array} & \text { Receptor } \\
\end{array}$ & No & \\
\hline Agpat9 & $\begin{array}{l}\text { Glycerol-3-phosphate } \\
\text { acyltransferase } 3\end{array}$ & No & 3T3L1(Ralston \& Mutch, 2015) \\
\hline Igfbp7 & $\begin{array}{l}\text { Insulin-like growth factor } \\
\text { binding protein } 7\end{array}$ & Yes & (Bou et al., 2017) \\
\hline Ctsc & $\begin{array}{l}\text { Cathepsin C/ Dipeptidyl } \\
\text { peptidase } 1\end{array}$ & Yes & \\
\hline Plin2 & Perilipin 2 & No & $\begin{array}{l}\text { Adipose tissue (Barneda, Frontini, Cinti, \& Christian, } \\
\text { 2013) }\end{array}$ \\
\hline Alcam & CD166 antigen & Yes & \\
\hline Ankef1 & $\begin{array}{l}\text { Ankyrin repeat and EF- } \\
\text { hand domain-containing } \\
\text { protein } 1\end{array}$ & No & \\
\hline
\end{tabular}




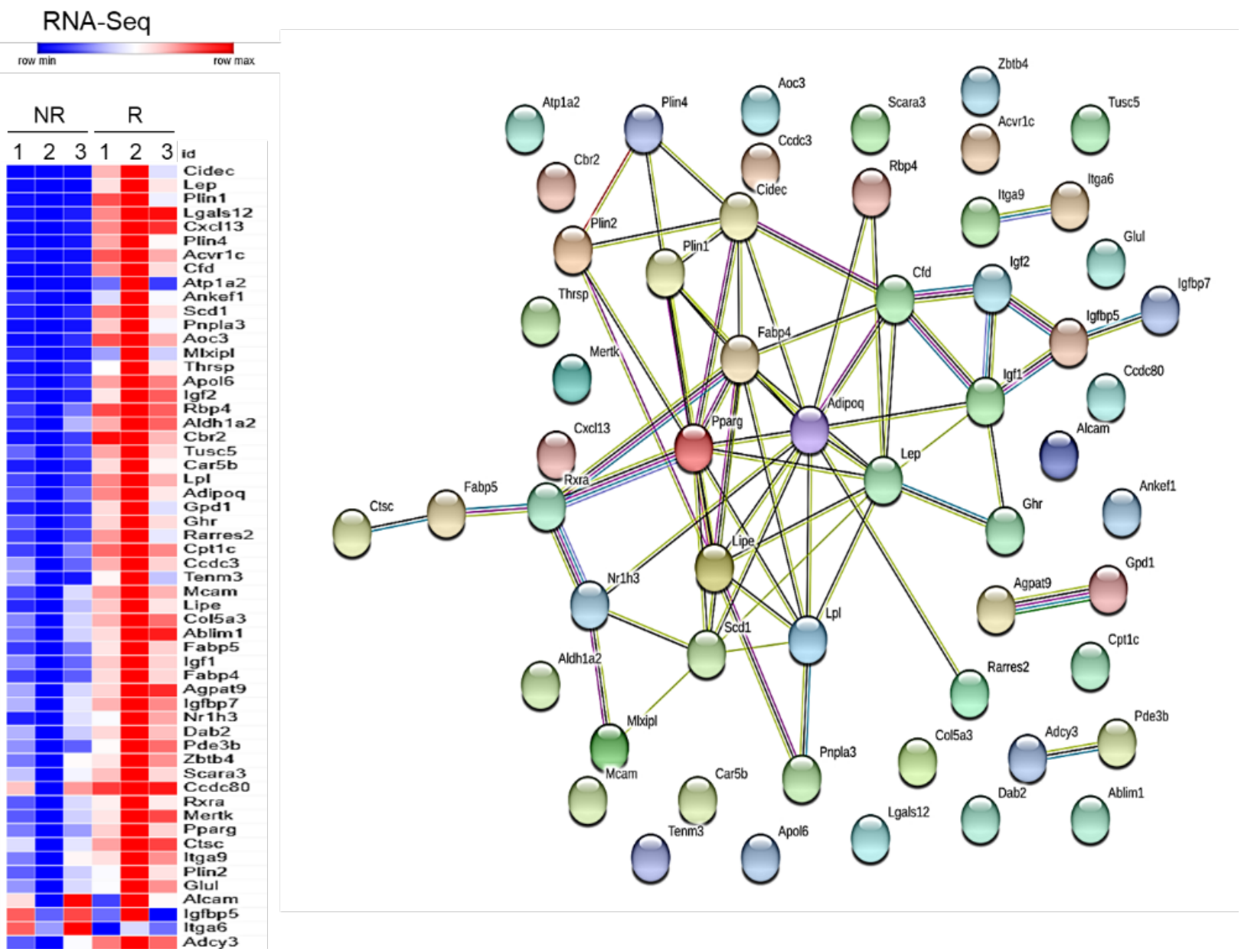

Figure 2. Differentially regulated adiposity related genes in radiated bones

(A) The right femoral metaphyses of C57BL/6 mice $(\mathrm{n}=3)$ were radiated $(24 \mathrm{~Gy})$ in a $5 \mathrm{~mm}$ region, while the equivalent region of the left leg served as control. R- and NR-femurs at day 21 post-radiation were harvested for mRNA isolation. (A) A curated list of genes that are reported to be expressed during adipocyte cell differentiation was used to generate a heat map of genes expressed in R-and NRbones detected by RNA-Seq. (B) A highly stringent STRING network representation of the BMAT-genes based on the curated heat map in (A), used for further validation by qRT-PCR.

\subsection{Longitudinal assessment of adiposity-related genes in radiated mouse bone tissue}

To confirm the longitudinal expression of BMAT-related genes post-radiation, we analyzed 20 selected genes (as shown in Fig.2B) on days 1, 7, 21 and 42 post-radiation. We observed a non-significant elevation in the transcriptional regulators, Pparg and Rxra on day1, followed by a sustained significant increase in both these genes on days 7, 21 and 42 (Fig. 3A). 
142 None of the other analyzed genes were significantly expressed on day 1 post-radiation. Significant up-

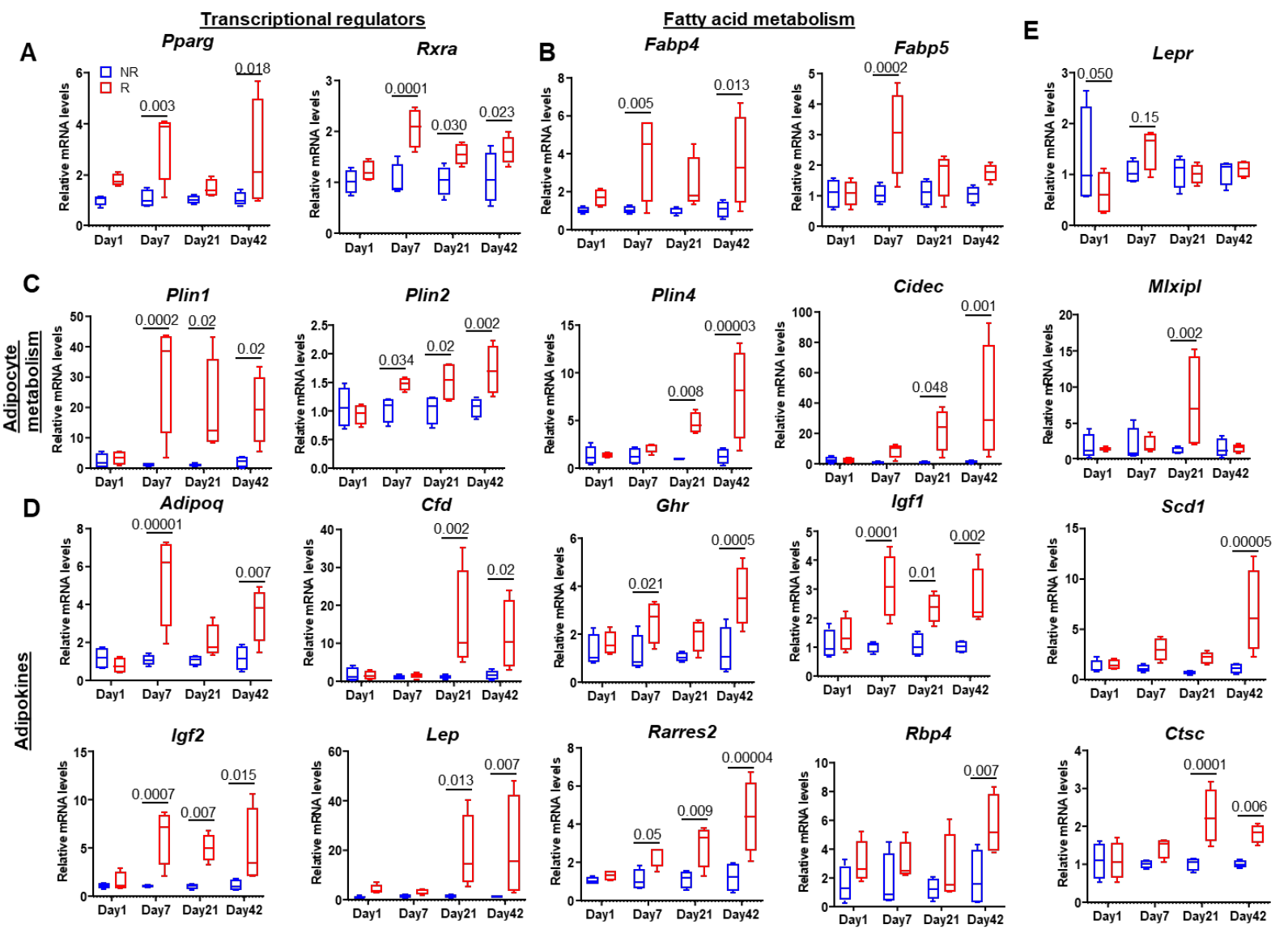

Figure 3. Longitudinal assessment of adiposity related genes in radiated bones

(A) The right femoral metaphyses of C57BL/6 mice were radiated (24Gy) in a $5 \mathrm{~mm}$ region, while the equivalent region of the left leg served as control. On days $1(n=4), 7(n=5), 21(n=5)$ and $42(n=4) R$ - and NR-femurs were harvested for mRNA isolation. qRT-PCR analysis is shown for genes involved with (A) transcription regulation of adipogenesis, (B) fatty acid metabolism, (C) adipocyte metabolism, (D) adipokines and (E) genes with miscellaneous functions during adipocyte differentiation. Results are expressed as medians with interquartile range. Statistical analyses were done using GraphPad Prism and p- values were calculated using a two-tailed, t-paired test.

regulation in adipose-associated genes related to metabolism and secretory adipokines was observed in R-

144 bones at day 7 (Adipoq, Fabp4, Fabp5, Ghr, Igf-1 and -2, Plin-1 and -2 and Rarres2), day 21 (Cfd, Ctsc, Igf-1 and -2, Lep, Mlxipl, Plin-1, -2 and -4 and Rarres2) and at day 42 (Adipoq, Cfd, Cidec, Ctsc, Fabp4, Ghr, Igf-1 and -2, Lep, Plin-1, -2 and-4, Rarres2, Rbp4 and Scd1) (Fig. 3 B-E). There were some genes which showed a non-significant elevation in R-bones at day 7 (Cidec, Lepr and Scd1) and at day 21 (Adipoq, Cidec, Fabp4, Ghr, Rbp4 and Scd1). 


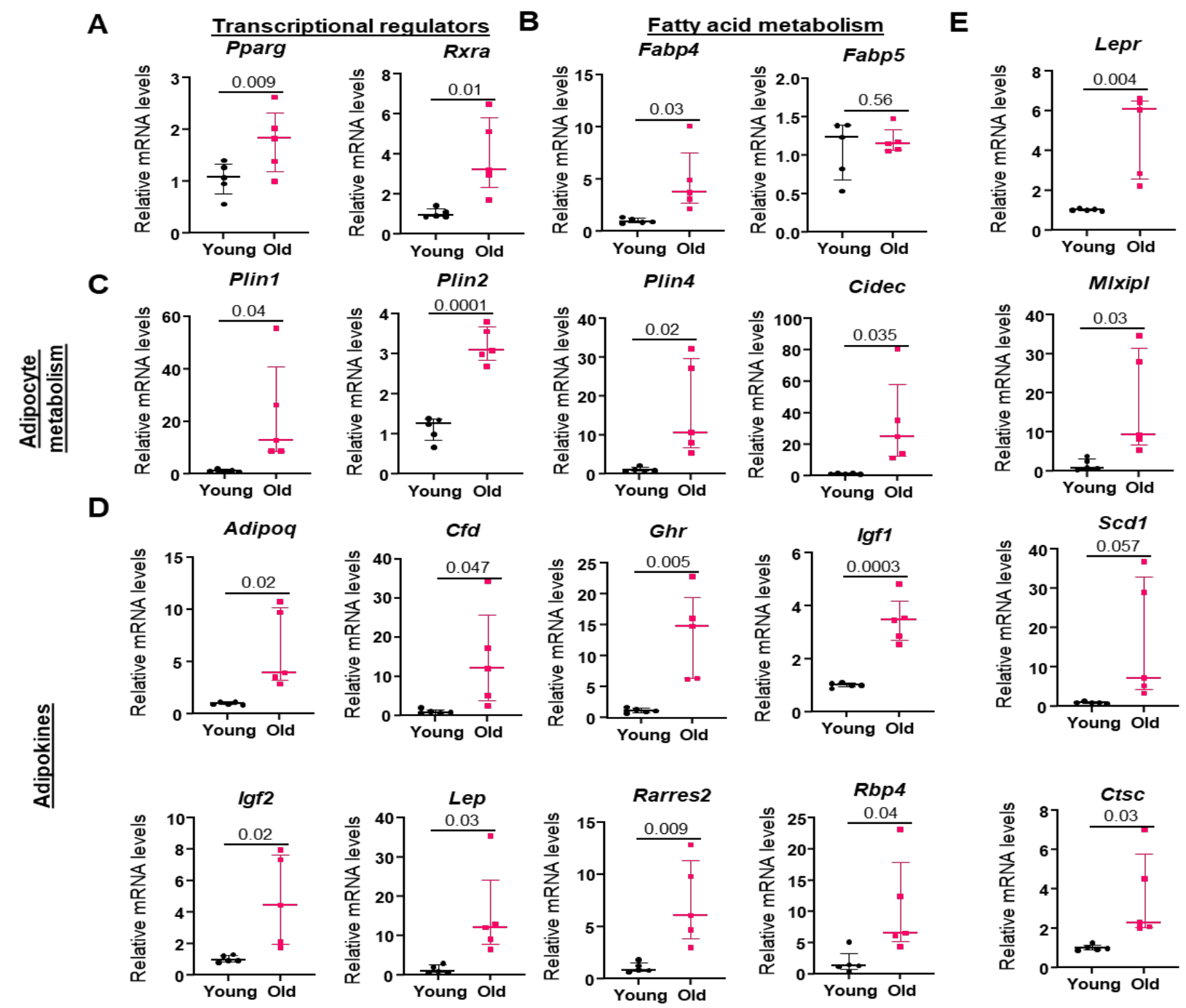

Figure 4. Longitudinal assessment of adiposity related genes with aging

Whole bones were collected from young $(5 \mathrm{~m})(\mathrm{n}=5)$ and old $(24 \mathrm{~m})(\mathrm{n}=5)$ mice and mRNA were isolated. qRT-PCR analysis is shown for genes involved with (A) transcription regulation of adipogenesis, (B) fatty acid metabolism, (C) adipocyte metabolism, (D) adipokines and (E) genes with miscellaneous functions during adipocyte differentiation. Results are expressed as medians with interquartile range. Statistical analyses were done using GraphPad Prism and p-values were calculated using a two-tailed unpaired t-test.

153 Rarres2, Rbp4 and Rxra) (Fig. 4A-D) were significantly upregulated, as compared to young (5m old) mouse

154 bone tissue. Unlike radiated bone, aged bone showed an $\sim 6$-fold increase in the Lepr (leptin receptor) (Fig.

4E). 

our previous report that high $p 21$ expression was seen at early time points post-radiation, while $p 16^{\text {Ink } 4 a}$

A

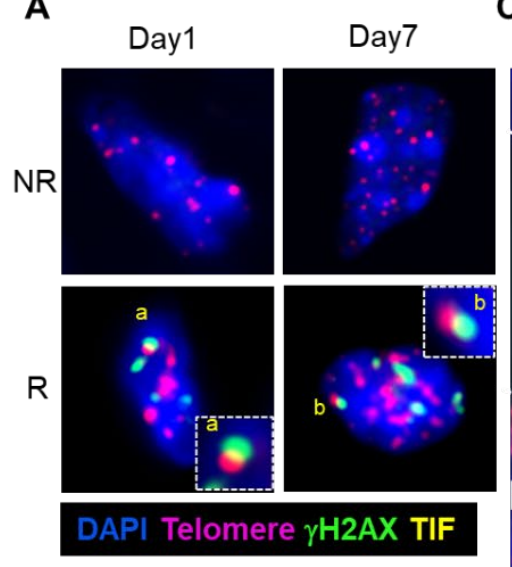

C

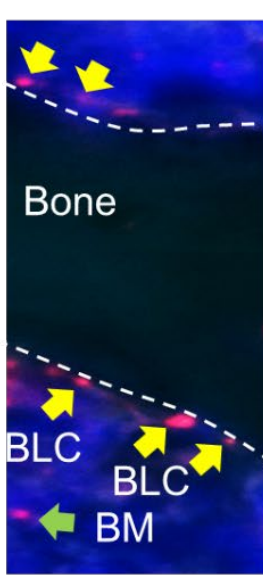

E

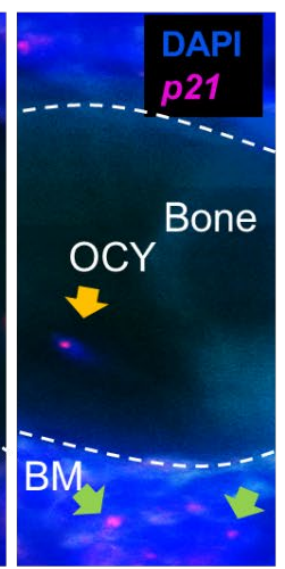

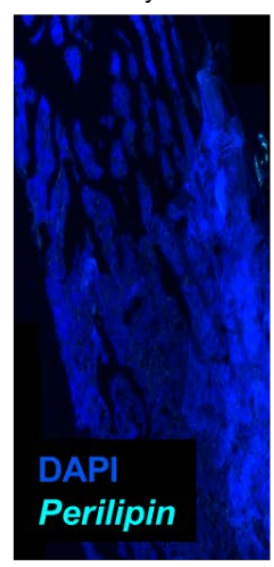

R

Day7

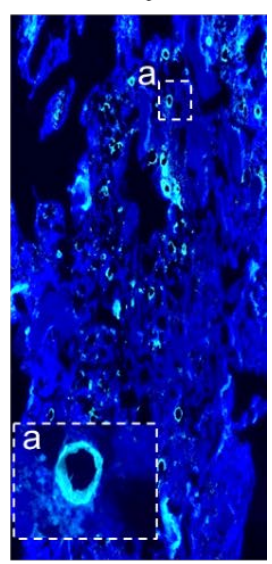

B

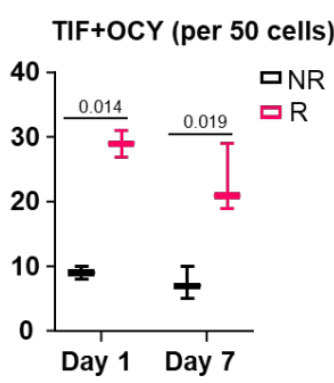

D

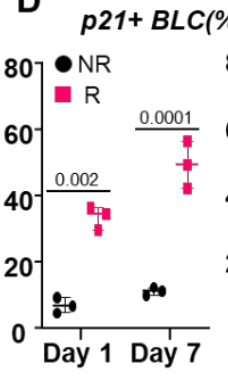

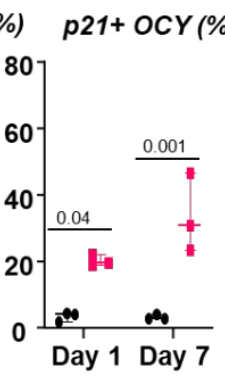

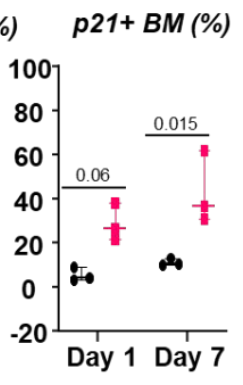

F

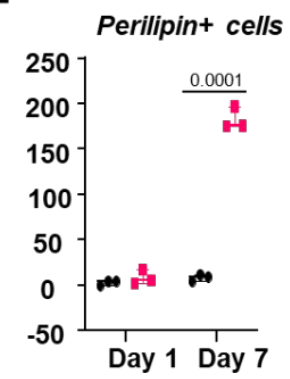

Figure 5. Longitudinal assessment of senescent cells and adipocytes in radiated bone tissue

To elucidate the earliest occurrence of cellular senescence post-radiation, R- and NR-bones were assessed for presence of senescent cells and adipocytes. (A, B) Colocalization of DNA damage at telomere sites, referred to as telomere dysfunction-induced foci (TIF), was visualized (A) and TIF+ osteocytes were quantified (B) at days 1 and 7 post-radiation. (C, D) RNA in-situ hybridization against Cdkn1a (p21) transcript was performed, visualized, and quantified in R- and NR-bones on days 1 and 7 and p21+ bone lining cells (BLC), osteocytes (OCY) and bone marrow (BM) cells (E, F) Perilipin stained adipocytes were assessed in NR- and R- bones. Negligible levels of adipocytes were identified in NR bones hence images are shown only for R-bones (E), while quantifications for both NR-and R-bones are presented (F). Results are expressed as medians with interquartile range. Statistical analyses were done using GraphPad Prism and p-values were calculated using a two-way ANOVA $(\alpha=0.05)$ with a Tukey post hoc analysis.

expression peaked at later time points (i.e., day 42; Supp. Fig. 2A). Assessing gene expression in 24-month bone samples, we detected high $p 21$ ( $\sim 6$-fold increase, $\mathrm{p}=0.0002)$ and high $p 16^{\operatorname{Ink} 4 a}(\sim 3.5$-fold increase, $\mathrm{p}=0.005$ ) gene expression as compared to 5 month old young bone samples (Supp. Fig. 2B). precedes BMAT, we performed the TIF assay, and observed significant up-regulation in $\mathrm{TIF}^{+}$osteocytes on day 1 and day 7 (Fig. 5A, B). The detection of the $p 21$ transcript was performed using RNA-ISH, and $p 21^{+}$-bone lining cells (BLCs), $p 21^{+}$-osteocytes (OCY) and $p 21^{+}$-bone marrow (BM) cells were detected 
A

Mouse Cdkn1a ENSMUST00000023829.6 3' UTR length: 1329

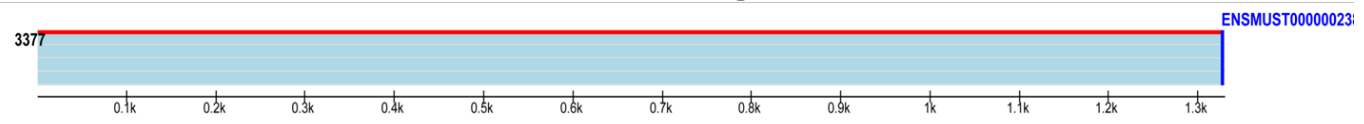

Conserved sites for miRNA families broadly conserved among vertebrates
miR.-499-5p
miR-291-3p $294-3 p / 295-3 p / 302-3 p$

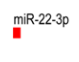

miR-291-3p/294-3p/295-3p/302-3p
miR-302-3p
miR-455-3p. 1

B

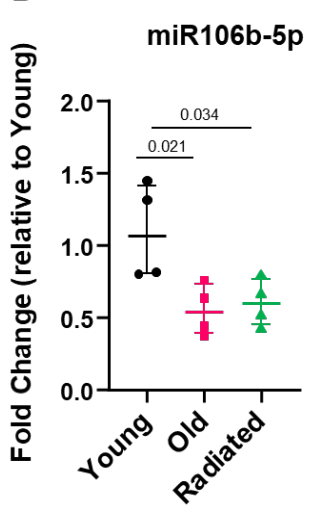

C

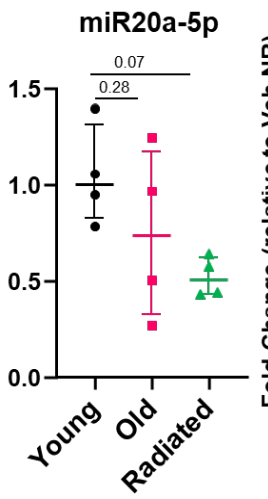

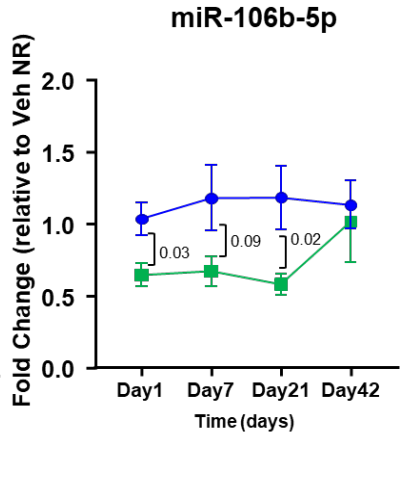

miR-20a-5p

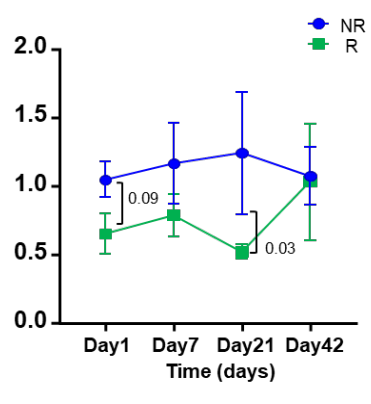

Figure 6. MicroRNAs targeting Cdkn1a are downregulated in radiated and aged bones

(A) A schematic showing microRNAs that bind to the 3' UTR of the senescence marker Cdkn1a (p21). (B) Whole bones were collected from young $(5 \mathrm{~m}, \mathrm{n}=4)$, old $(24 \mathrm{~m}, \mathrm{n}=4)$ and radiated $(5 \mathrm{~m}$ old, $\mathrm{n}=4)$ mice and mRNA were isolated. The cDNA was prepared using a miR reverse transcriptase kit and qRT PCR was performed using the primers for miR-106b-5p and miR-20a-5p. While miR-106b-5p was significantly reduced in both old- and R-bones, miR-20a-5p showed a trend to decrease in old bones but reduced significantly in radiated bones. Statistical analyses were done using GraphPad Prism and p values were calculated using a oneway ANOVA $(\alpha=0.05)$ with a Bonferroni post hoc analysis. (C) To test the expression of miRs longitudinally, the right femoral metaphyses of C57BL/6 mice were radiated (24Gy) in a $5 \mathrm{~mm}$ region, while the equivalent region of the left leg served as control. On days $1(n=4), 7(n=5), 21(n=5)$ and $42(n=4)$ R- and NR-femurs were harvested for total mRNA isolation and the cDNA was prepared using a miR reverse transcriptase kit and qRT PCR was performed using the primers for miR-106b-5p and miR-20a-5p. Expression levels of both miR-106b$5 p$ and miR-20a-5p in R-bones remained lower than NR-bones on all time points except day 42, with significant changes seen only on day 21 . Results are expressed as medians with interquartile range. Statistical analyses were done using GraphPad Prism and p values were calculated using multiple t-tests.

Based on their binding at the 3' UTR of $p 21$, miRs were selected on their preferentially conserved targeting 
$174106 b-5 \mathrm{p}$ (targeting $\mathrm{p} 21$ mRNA) was observed both in aged- $(\mathrm{p}=0.03)$ and R-bones $(\mathrm{p}=0.038)$, while mir-

$17520 a-5 p$ showed a non-significant decrease in old-bones $(\mathrm{p}=0.28)$, but a significant reduction in R-bones

$176(\mathrm{p}=0.009)$ when compared to young-NR bone samples (Fig. 6B). The mir-106b-5p was substantially

177 reduced at different time points in the radiated bone tissue (day $1[\mathrm{p}=0.03]$, day 7 [p=0.09] and day 21

$178[\mathrm{p}=0.02])$, while mir-20a-5p was significantly down-regulated only at day 21 post-radiation $(\mathrm{p}=0.03)$ but

179 had reduced expression throughout at day $1(\mathrm{p}=0.09)$ and day 7 as well (Fig. 6C).

A

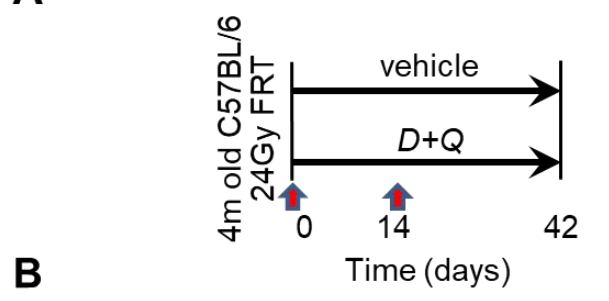

B

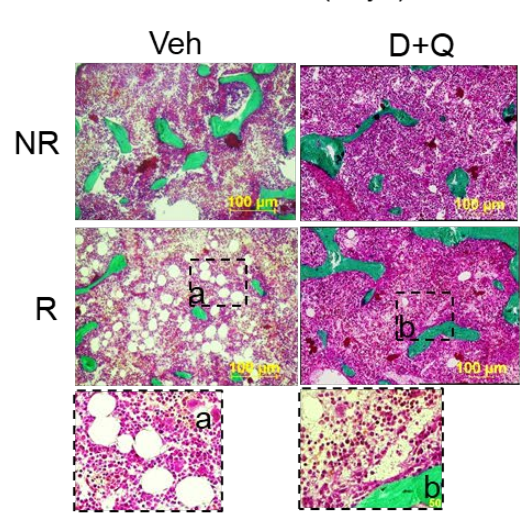

D
C

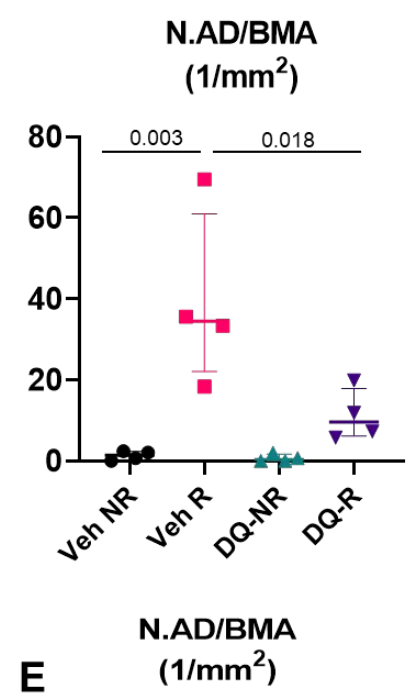

ADVol.Pm/BMA

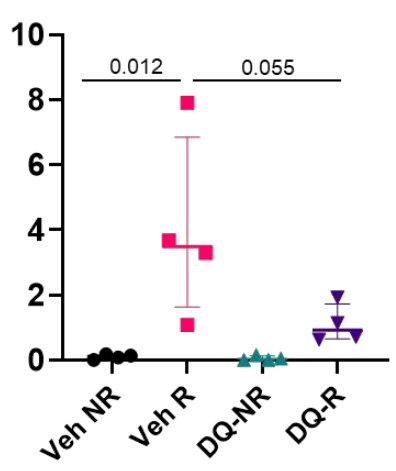

ADVol.Pm/BMA

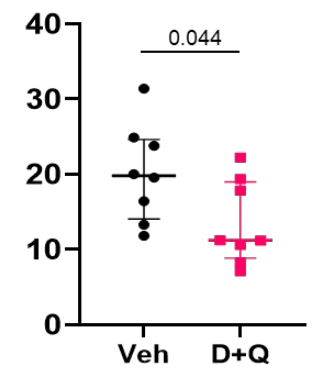

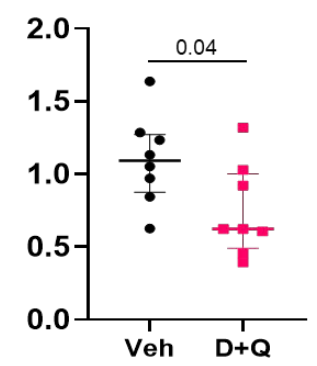

Figure 7. Suppression of senescent cell burden ameliorates bone marrow adiposity in radiated and aged bone tissues (A) A schematic representing the experimental design in which right femoral metaphyses of C57BL/6 mice were radiated $(24 \mathrm{~Gy})$ in a $5 \mathrm{~mm}$ region, while the equivalent region of the left leg served as control. Animals were treated with either vehicle $(n=4)$ or $D+Q(n=4)$ on days 0 and 14 post radiation and bones were analyzed histologically on day 42 . (B) Representative images from plastic embedded 5 um bone sections stained with Goldner's trichrome stain are shown. (C) Quantification of adipocyte number and adipocyte volume normalized against the bone marrow area (BMA). Results are expressed as medians with interquartile range. Statistical analyses were done using GraphPad Prism and p-values were calculated using a two-way ANOVA $(\alpha=0.05)$ with Dunnett's post hoc analysis. (D) Schematic representation of experimental design in which 20-month old C57BL/6 received either vehicle or D+Q once a month for 4-months, and afterward the bones were processed for histomorphometry. (E) Adipocyte histomorphometric assessments are also presented for aged bones. Statistical analysis was performed using unpaired two-tailed t-test. 

available under aCC-BY 4.0 International license.
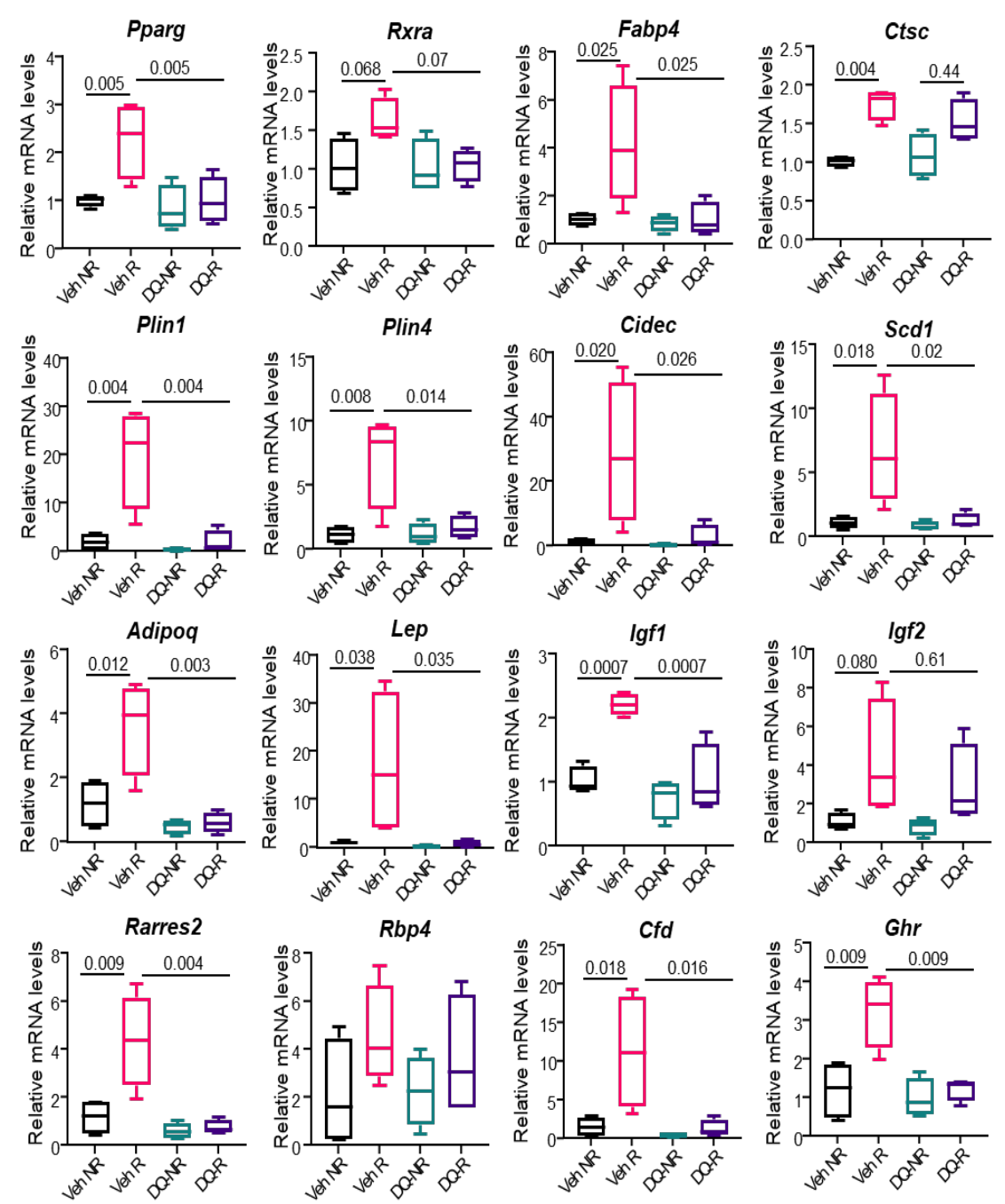

Figure 8. Suppression of senescent cell burden decreases BMAT-related gene expression in radiated bones

Right femoral metaphyses of C57BL/6 mice were radiated (24Gy) in a $5 \mathrm{~mm}$ region, while the equivalent region of the left leg served as control. Animals were treated with either vehicle $(n=4)$ or $D+Q(n=4)$ on days 0 and 14 post radiation and bones were harvested for mRNA. qRT-PCR was performed for 16 BMAT-related genes. Results are expressed as medians with interquartile range. Statistical analyses were done using GraphPad Prism and p values were calculated using a two-way ANOVA $(\alpha=0.05)$ with a Dunnett's post hoc analysis.

BMAT is a common observation following radiation exposure and aging. We have showed previously that intermittent treatment with the senolytic cocktail of D+Q can suppress senescent cell burden and alleviate deleterious changes in bone architecture during aging (Farr et al., 2017) and post-focal radiation (A. Chandra et al., 2020a). Here, intermittent treatment with D+Q following 24Gy focal radiation (Fig. 7A) reduced BMAT, as measured by adipocyte number and volume, and normalized against the bone marrow 
marrow adiposity.

\subsection{Adipose-related miR-27a-3p is dependent on a senescence-driven microenvironment}

A

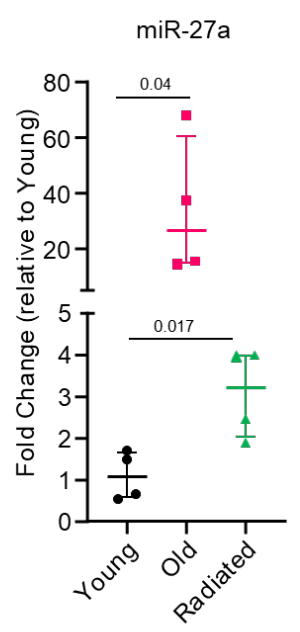

B

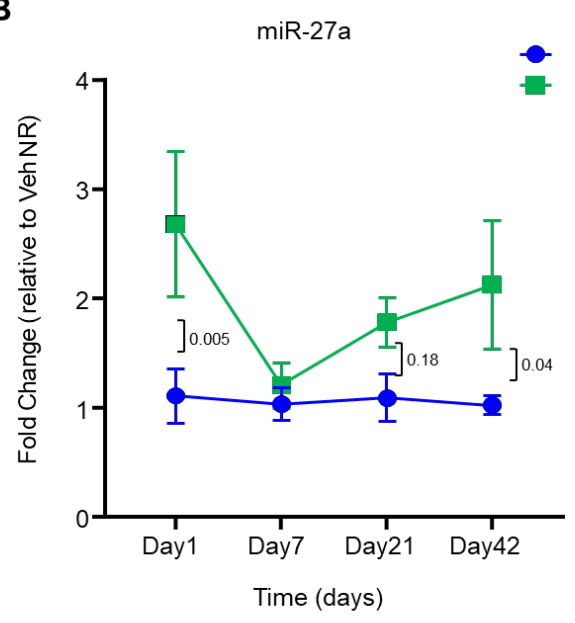

C

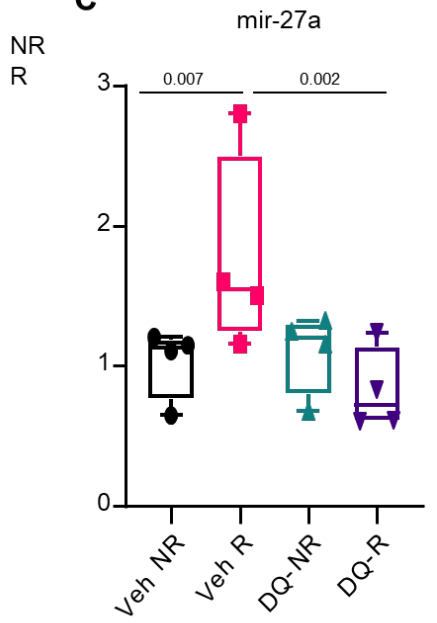

Figure 9. Adiposity related MicroRNA 27a is positively correlated with senescence

Whole bones were collected from young $(5 \mathrm{~m})$, old $(24 \mathrm{~m})$ and radiated (5m old) mice and mRNA was isolated. The cDNA was prepared using a miR reverse transcriptase kit and qRT PCR was performed using primers for miR-27a (A). Statistical analyses were done using GraphPad Prism and $\mathrm{p}$ values were calculated using unpaired t-test comparing young vs old and young vs radiated. (B) The right femoral metaphyses of C57BL/6 mice were radiated (24Gy) in a $5 \mathrm{~mm}$ region, while the equivalent region of the left leg served as control. On days $1(n=4), 7(n=5), 21(n=5)$ and $42(n=4) R-$ and NRfemurs were harvested for total mRNA isolation. The cDNA was prepared using a miR reverse transcriptase kit and qRT PCR was performed using primers for miR-27a. Results are expressed as medians with interquartile range. Statistical analyses were done using GraphPad Prism and p values were calculated using a multiple-t-test. (C) Right femoral metaphyses of C57BL/6 mice were radiated (24Gy) in a $5 \mathrm{~mm}$ region, while the equivalent region from the left leg served as control. Animals were treated with either vehicle $(n=4)$ or $D+Q(n=4)$ on days 0 and 14 post radiation and bones were harvested for mRNA. The cDNA was prepared using a miR reverse transcriptase kit and qRT PCR was performed using primers for miR-27a. Results are expressed as medians with interquartile range. Statistical analyses were done using GraphPad Prism and $p$ values were calculated using a two-way ANOVA $(\alpha=0.05)$ with a Dunnett's post hoc analysis. 
different time points (day $1[p=0.005]$, day $21[p=0.18]$ and day $42[p=0.04]$ (Fig. 9B). Treatment with the senolytic cocktail of $\mathrm{D}+\mathrm{Q}$ suppressed the upregulation seen in mir-27a-3p levels in bones at 4 weeks postradiation (Fig. 9C).

\section{Discussion}

203 Bone is a metabolically active tissue with numerous cell types and a complex interplay of pathways that maintain an intricate balance of bone formation and resorption. Mesenchymal progenitors which generally contribute to bone formation also differentiate into marrow adipocytes, thereby causing a relative reduction in the osteoblast progenitor pool and disrupting bone homeostasis under conditions where adipogenesis is favored over osteogenesis. Increase in BMAT is a change observed across all instances of osteoporosis, is associated with reduced bone quality and fractures, and has been used as a predictor of osteoporosis (Milisic, Vegar-Zubovic, \& Valjevac, 2020; Woods et al., 2020). Our previous studies support the idea that increased BMAT depletes the limited MSC pool and that MSCs undergo lineage switching toward an

211 adipogenic cell fate in an aging microenvironment (A. Chandra et al., 2017; Singh et al., 2016).

212 Interestingly, it was recently shown that conditional deletion of Ppar from early mesenchymal progenitors

213 reduced BMAT but did not ameliorate thiazolidinedione- or age- associated bone loss leading the authors

214 to a conclusion that increasing BMAT does not contribute in age-associated bone loss (Almeida et al.,

215 2020). In contrast, deletion of BMAT by targeting adiponectin (Adipoq) expressing marrow cells was

216 shown to induce bone mass resulting in an osteosclerotic condition (Zou et al., 2020). Furthermore, targeted

217 deletion of Ppary in Dermo1 expressing mesenchymal lineage cells was shown to alleviate age-induced

218 cortical bone loss in mice(Cao et al., 2020). Overall, these studies suggest that BMAT seem to have a

219 correlation with age-related bone loss, however the trigger for BMAT during aging is still unknown.

220 In this study we identify cellular senescence as an important and early trigger of MSC cell fate switching

221 toward adipogenesis during bone aging, using longitudinal assessments of senescence and BMAT-related

222 genes in radiated bones (a model for clinical radiotherapy and accelerated bone aging), with parallel

223 comparisons in aging bone. We have previously described the correlation between oxidative stress-induced

224 DNA damage, a trigger for cellular senescence, and elevated levels of BMAT, as well as a reduction in 
225

226

227

228

229

230

BMAT with improved bone architecture (A. Chandra et al., 2017; A. Chandra et al., 2018). Downregulation of WRN, a RecQ-type DNA helicase and DNA-repair protein, activates adipocyte-related genes in the pre-adipocyte cell line 3T3-L1 (Turaga et al., 2009). Moreover, we have shown that an aged microenvironment influences the fate of young transplanted MSCs towards adiposity (Singh et al., 2016). In this study our RNA Seq data indicated that several BMAT-related genes were upregulated 3-weeks postradiation. As shown in Table 1 several genes are associated with in vitro adipocyte differentiation, but not all are studied in the context of BMAT function in vivo. We showed a significant elevation of expression among these genes in R-bones as shown by RNA-Seq data (Fig.2 A) and confirmed the relevance of select few in an adipocyte differentiation assay in human MSCs (Supplementary Fig. 1). A time course in radiated bones revealed that expression levels of these BMAT-related genes varied, but became more significant after 42 days, with 17 out of the 20 tested showing significant up-regulation. Plin1 staining in R-bones suggested that Plin1+ adipocytes were significantly elevated at day 7 post-radiation, but non-existent at day1 (Fig.5 E, F). This supported the gene expression data showing 11 of 20 BMAT genes being significantly upregulated at day7 but not at day1. Similarly, 18 of the tested 20 BMAT-related genes were markedly up-regulated in $24 \mathrm{~m}$ old bones. Lepr was one of the genes significantly expressed in the old but not R-bones, suggesting some slight underlying differences between aging and radiation effects. Histologically, R-bone and aged bone look identical (A. Chandra et al., 2019), but this is the first evidence to our knowledge that shows an almost mirrored expression pattern in the BMAT-related genes between the two models. To understand the advent of aging-related changes to oxidative stress related cellular senescence and BMAT, we used focal radiation as a surrogate, which allowed us to assess these changes longitudinally. Our data clearly show that senescence is established on day 1 in R-bones, shown by expression of p21 mRNA using qRT-PCR (Supp. Fig.2 A), p21 RNA-ISH in different cells of the bone marrow compartment (Fig.5C,D), and dysfunctional telomeres in osteocytes (Fig.5A,B). It has been shown through in vitro experimentation that $\mathrm{p} 21$ is essential during adipocyte differentiation where it not only induces cell cycle arrest but also maintains adipocyte hypertrophy (Inoue et al., 2008). Here we show that p21 expression on day 1 precedes appearance of adipocytes on day 7 post-radiation. 


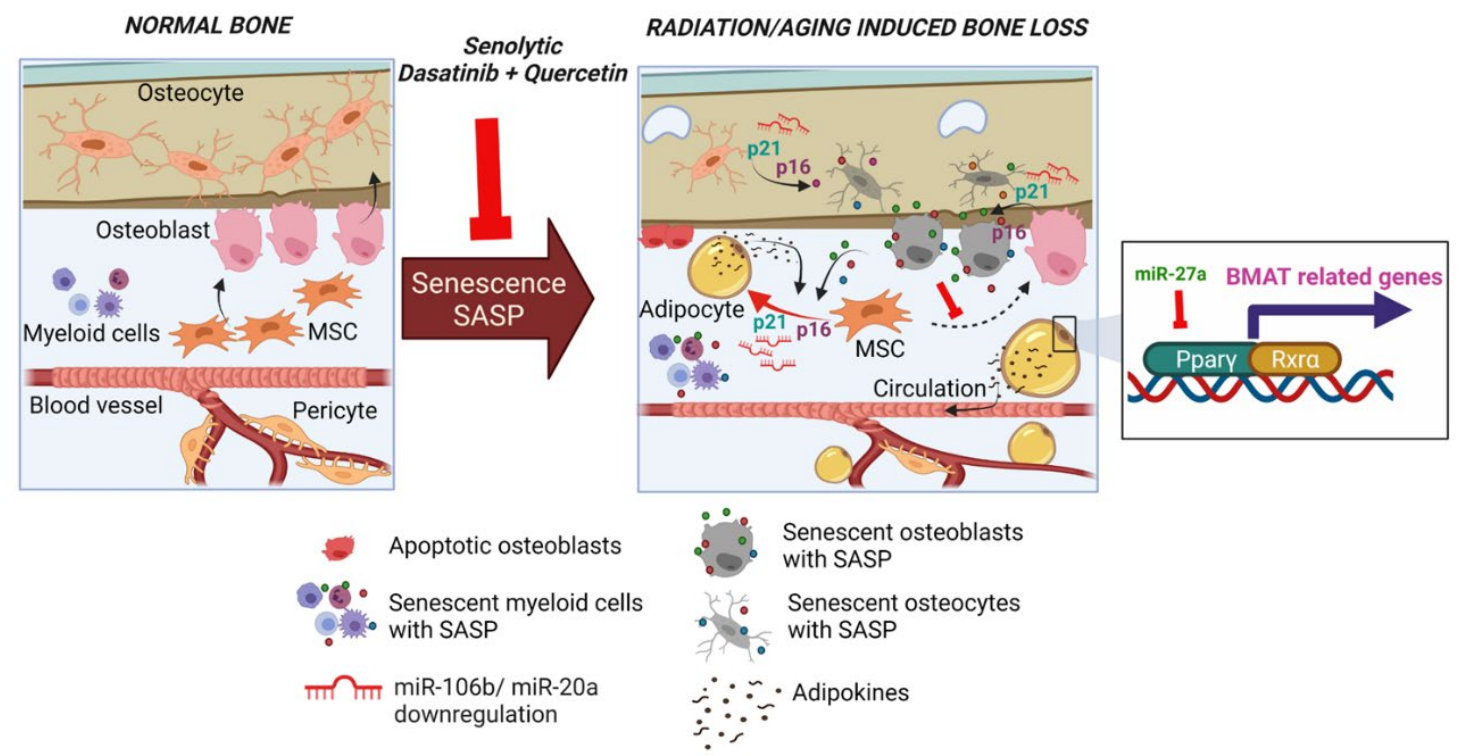

Figure 10. Schematic

The schematic represents changes in an oxidatively stressed, senescent microenvironment in which mesenchymal progenitors are preferentially forming adipocytes, regulated by a common process shared between aging bone and radiation-induced bone damage, and with identical expression patterns of BMAT-related genes and miRs. Increase in senescent markers p21 and p16Ink4a induce a cellular state in which production of the SASP increases and influences the bone marrow environment. Secreted adipokines can promote MSC fate switching to an adipocyte lineage. Several adipokines are also released in circulation, causing systemic effects. These changes in senescence markers and genes that regulate BMAT are in turn regulated by their corresponding miRNAs. These changes can be blocked or reversed by the clearance of senescent cells using senolytic drugs. The figure was created with BioRender.com.

251 (A. Chandra et al., 2020b; Farr et al., 2017)We also report here that the miRs that regulate $p 21, m i R-106 b-$ points post-radiation and with aging.

254 Genetic clearance of $p 16^{\text {Ink4a }}$ senescent cells has been shown to reduce age-related BMAT (Farr et al., 2017).Reduction in the senescent cell burden by a senolytic cocktail of $D+Q$ has been shown to reduce both $p 21$ and $p 16^{\operatorname{Ink} 4 a}$ transcripts as well as the SASP (A. Chandra et al., 2020b). Pharmacological treatment with the senolytic cocktail D+Q effectively clears senescent cells and suppresses the SASP in radiated (A. Chandra et al., 2020b) and aged (Farr et al., 2017) bones. Here we report that pharmacological treatment with $\mathrm{D}+\mathrm{Q}$ significantly reduced radiation- and age-related adipocyte number and volume when normalized against the bone marrow area. Even though it is assumed that BMAT related genes correlate well with adipocyte numbers, we used our radiation model and tested the BMAT related genes following senescent cell clearance by D+Q. As conceptualized in a schematic (Fig.10), p21/miR-106b/miR-20a regulation drives cellular senescence in several bone marrow cells. As shown by Inoue and colleagues (Inoue et al., 2008), regulation of p21 may regulate adipocyte/BMAT related genes and thereby regulate MSC cell fate, 
which is also seen in R-bones. Since, by day 42, expression levels of miR-106b or miR-20a in the R-bones returned to baseline levels seen in the controls, we could not assess the effects of $\mathrm{D}+\mathrm{Q}$ on either of these miRNAs. Furthermore, suppression of the SASP by D+Q (A. Chandra et al., 2020b) reduces adipokine expression and potential secretion further regulating MSC cell fate (Fig. 10). Since BMAT accumulation is inversely proportional to the MSC population and bone mineral density (A. Chandra et al., 2017), molecular regulation of BMAT could become a potential therapeutic option to treat age- and disease-related 271 osteoporosis.

272 To identify an upstream molecular regulator of BMAT we studied mir-27a-3p, a miR that regulates Pparg and Rxra, expecting for this miR to decrease. Interestingly, we observed an increase in the levels of $m i R$ -

$27427 a-3 p$ both in R- and aged- bones. However, this was consistent with several reports showing elevation of $275 m i R-27 a-3 p$ seen during adipocyte differentiation or in adipose tissue (Yu et al., 2018). Since the primary target of $m i R-27 a-3 p$ is Pparg and Rxra, the increased levels of $m i R-27 a-3 p$ was thus an indicator of increased BMAT in which the miR-based downregulation of target genes occurs in synchrony. Hence, it is now understood that an elevated $m i R-27 a-3 p$ is a cellular negative feedback response to curb adipogenesis and counter Pparg or Rxra (Deng et al., 2020). Interestingly, the senolytic cocktail of D+Q downregulated $m i R-27 a-3 p$, and most of the radiation-induced BMAT genes, suggesting a direct correlation of senescent cells and elevation of BMAT. Interestingly, phosphodiesterase 3B (Pde3B), was the only BMAT related gene (Fig.2A, Table1) that was predicted to be regulated by both miR-106b/mir-20a and mir-27a-3p (TargetScanMouse7.1) with binding sites in the 3'UTR of the Pde3b gene. Pde3b has been shown to be indispensable during the maintenance of the inflammatory nature of the adipose tissue (Ahmad et al., 2016), and hence may play a role in the regulation of inflammatory cytokines including adipokines. Some of these cytokines which are part of the inflammasome may be traditional SASP factors, but some of them can be 287 characterized as novel SASP factors.

288 Adipokines, the adipocyte derived hormones, also referred to as inflammatory cytokines secreted by the 289 adipocytes, have detrimental effects on bone homeostasis. It is well understood now that adipokines and 290 other secreted proteins from adipocytes interact with other cell types in the bone in a paracrine function, and potentially other organs of the body in a systemic manner (MacDougald \& Burant, 2007). Adipokines 
are known to potentiate the formation of new adipocytes and are often inflammatory in nature. Amongst sequence predicted by the Signal P software, suggesting that these proteins could be potential adipokines (Table1).Chemerin is one such adipokine, which has been studied extensively. Early reports showed that the Chemerin (Rarres2) gene and its receptor gene CMKLRl (chemokine like receptor-1), were expressed in several organs (Bozaoglu et al., 2007) and cell types, including pre-adipocytes, macrophages and mature adipocytes (MacDougald \& Burant, 2007). In our studies Rarres2 expression increased in R-bones in a sequential manner, while being significantly expressed in the old-bones. Chemerin has been shown to induce osteoclastogenesis, and a neutralizing antibody against Chemerin blocks this process gene), Adipsin (Cfd gene), Adiponectin (Adipoq gene), Visfatin (Nampt gene) and Vaspin (Serpina12 gene)

314 thus become a potential therapeutic to target age- and disease-related bone loss.

\section{4. Materials and Methods}

\subsection{Animal study design}


All animal studies were approved by the Institutional Animal Care and Use Committee at the Mayo Clinic.

The animals were purchased from The Jackson Laboratory and housed in our facility at $23-25^{\circ} \mathrm{C}$ with a 12 h light/dark cycle and were fed with standard laboratory pellets with free access to water. Four-month-old C57BL/6 mice received focal radiation as a single dose of 24Gy on day 0. Using X-Rad-SmART (Precision X-Ray (PXi), North Branford, Connecticut) an image-guided focal dose of $24 \mathrm{~Gy}$ at $6.6 \mathrm{~Gy} / \mathrm{minute}$ was delivered to a $5 \mathrm{~mm}$ region of the distal metaphyseal region of the right femur, while the left femur served as the contralateral control. Bones were harvested at day 1, 7,21 and 42 for gene expression and RNA sequencing (day 21). Additional animals were radiated, and bones were collected on days 1 and 7 for histology and RNA-in situ hybridization (ISH). To test the effect of senolytic cocktail Dasatinib (D, $5 \mathrm{mg} / \mathrm{kg})$ and Quercetin $(\mathrm{Q}, 50 \mathrm{mg} / \mathrm{kg})$ on radiation-induced BMAT related genes, $\mathrm{D}+\mathrm{Q}$ was dosed on day 0 and day 14 post-radiation as described previously, and bones were collected on day 42 post-radiation (A. Chandra et al., 2020b). To test the effect of D+Q on age-related BMAT, 20 month-old C57BL/6 mice were injected with vehicle or D+Q once monthly for 4 months as described previously (Farr et al., 2017), with assessments of BMAT performed in the vertebra.

\subsection{RNA preparation, sequencing, and bioinformatics}

A $5 \mathrm{~mm}$ region below the growth plate of the distal metaphyseal femur was cut out from the radiated (R) and non-radiated (NR) legs. After removal of muscle tissue, the bone samples were homogenized and total RNA was isolated using RNeasy Mini Columns (QIAGEN, Valencia, CA) for subsequent RNAsequencing, which was performed by the Mayo Sequencing Core. MAP-RSeq version 3.0.2 (Kalari et al., 2014), an integrated RNA-Seq bioinformatics pipeline developed at the Mayo Clinic, was used for comprehensive analysis of raw RNA sequencing paired-end reads. MAP-RSeq employed STAR (Dobin et al., 2013), the very fast, accurate and splice-aware aligner for aligning reads to the reference mouse genome, build mm10. The aligned reads were then processed through multiple modules in a parallel fashion. Gene and exon expression quantification was performed using the Subread (Liao, Smyth, \& Shi, 2013) package to obtain both raw and normalized (FPKM - Fragments Per Kilobase per Million mapped) reads. STARFusion, a module to detect fusions in STAR (Dobin et al., 2013), was used to identify and report any 
343

344

345

346

347

348

349

350

351

352

353

354

355

356

357

358

359

360

361

362

363

364

365

366

367

expressed gene fusions in the samples. Likewise, expressed single nucleotide variants (SNVs) and small insertions-deletions (INDELs) were detected using a combination of bioinformatics tools such as GATK (McKenna et al., 2010), HaplotypeCaller(McKenna et al., 2010) and RVBoost (C. Wang et al., 2014). Finally, comprehensive quality control modules from the RSeQC(L. Wang, Wang, \& Li, 2012) package were run on the aligned reads to assess the quality of the sequenced libraries. Results from these modules described above were linked through a single html document and reported by MAP-RSeq.

R bioinformatics package DESeq2 (Love, Huber, \& Anders, 2014) was used for differential gene expression analysis. The criteria for selection of significant differentially expressed genes were p-adjusted $\leq 0.05$ and $\mid \log 2$ fold change $\mid \geq 1.5$. The RNA-Seq data has been uploaded on the GEO database (https://www.ncbi.nlm.nih.gov/geo/query/acc.cgi?acc=GSE180076).

\subsection{Adipocyte differentiation assay}

Human MSCs were maintained in growth media (Dulbecco's Modified Eagle Medium (DMEM, Gibco) containing D-glucose $(1 \mathrm{~g} / \mathrm{L})$, L-Glutamine and sodium pyruvate $(110 \mathrm{mg} / \mathrm{L}))$ supplemented with $10 \%$ fetal bovine serum (Gibco). For adipocyte differentiation, cells were cultured in growth media supplemented with indomethacin $(60 \mu \mathrm{M})$, Isobutyl methylxanthine $(500 \mu \mathrm{M})$, dexamethasone $(1 \mu \mathrm{M})$ and insulin $(10 \mu \mathrm{g} / \mathrm{ml})$. Cells were cultured in growth media or adipocyte differentiation media for 14days. Adipocyte differentiation was confirmed by visually confirming the lipid droplet accumulation by oil red staining (Supp. Fig.1A). From a parallel culture mRNA was collected from control $(n=2)$ and adipogenic differentiated cells $(n=2)$ for gene expression analysis.

\subsection{Telomere fluorescence in situ hybridization (FISH) and DNA damage}

Paraffin embedded bone sections were de-paraffinized followed by serial hydration in $100 \%$ and $70 \%$ ethanol, with final hydration in PBS. Antigen was retrieved by incubation in $0.01 \mathrm{M}$ citrate buffer (pH 6.0) at $95^{\circ} \mathrm{C}$ for $15 \mathrm{~min}$, placed on ice for $15 \mathrm{~min}$ and then washed in water and PBS for 5 min each. Subsequently, blocking buffer was applied (normal goat serum 1:60 in PBS/BSA, \#S-1000; Vector 
Laboratories) for 30min at room temperature (RT) followed by primary antibody $(\gamma-\mathrm{H} 2 \mathrm{~A} . \mathrm{X}$, Cell Signaling, $\mathrm{mAb} \# 9718$ ) overnight at $4{ }^{\circ} \mathrm{C}$. Slides were washed three times with PBS and incubated for 60 min with a species-specific secondary antibody (no. PK-6101; Vector Lab). Sections were then washed 3 times in PBS

371 for 5 min and Cy5 Streptavidin (1:500 in PBS, No: SA-1500, Vector Lab) was applied for 25 min followed

372 by three washes in PBS, crosslinking with $4 \%$ paraformaldehyde for 20 min and dehydration d in graded

373 ethanol. Sections were denatured for $10 \mathrm{~min}$ at $80^{\circ} \mathrm{C}$ in hybridization buffer $[70 \%$ formamide (Sigma UK),

$37425 \mathrm{mM} \mathrm{MgCl} 2,0.1 \mathrm{M}$ Tris (pH 7.2), 5\% blocking reagent (Roche, Germany)] containing $2.5 \mu \mathrm{g} / \mathrm{mlCy}-3-$

375 labelled telomere-specific (CCCTAA) peptide nucleic acid probe (Panagene), followed by hybridization

376 for $2 \mathrm{~h}$ at RT (minimum) in a humidified chamber in the dark. Next, slides were washed once with $70 \%$

377 formamide in $2 \times \mathrm{SSC}$ for $10 \mathrm{~min}$, followed by 1 wash in SSC and PBS for $10 \mathrm{~min}$. Sections were mounted 378 with Dapi (ProLong ${ }^{\text {TM }}$ Diamond Antifade Mountant, Invitrogen, P36962). In-depth Z-stacking was used (a 379 minimum of 135 optical slices using a $63 \mathrm{X}$ objective). Number of TIFs per cell was assessed by manual 380 quantification of partially or fully overlapping (in the same optical slice, Z) signals from the telomere probe and $\gamma \mathrm{H} 2 \mathrm{~A} . \mathrm{X}$ in z-by-z analysis. Images were deconvolved with blind deconvolution in AutoQuant X3

382 (Media Cybernetics).

383 For Formalin-Fixed Paraffin-Embedded (FFPE), immunohistochemistry was carried out following an overnight incubation with rabbit monoclonal anti-perlipin1 (1:100, Cell Signaling Technology, 9349). The next day following three washes, tissues were incubated with a species-specific secondary antibody (Alexa 647) for $1 \mathrm{~h}$ then washed 3 times with PBS and mounted using ProLong Gold Antifade Mountant with DAPI

387 (Invitrogen).

\subsection{RNA in situ hybridization (RNA-ISH) and Immunohistochemistry}

RNA-ISH was performed per the RNAScope protocol from Advanced Cell Diagnostics Inc. (ACD): 
570 (Cy 3 Range), then blocked to perform the next amplification in another channel, p16/p19 (CDKN2A)

C3 using Opal 650 (Cy5). Tissue sections were then mounted using ProLong Gold Antifade Mountant with

DAPI (Invitrogen). Sections were imaged using in-depth Z stacking.

\subsection{Quantitative RT-PCR}

A $5 \mathrm{~mm}$ region below the growth plate of the distal metaphyseal femur was cut out from the radiated and the non-radiated legs. After removal of muscle tissue, the bone samples were stored in TRIzol (Invitrogen) at $-80^{\circ} \mathrm{C}$. Bones were homogenized and total RNA was isolated using a phase separation method, followed spectrophotometer with A260/230 $\geq 1.6$ and A260/A280 set at $\geq 1.8$ (Thermo Scientific, Wilmington, DE).

Biosystems by Life Technologies, Foster City, CA), according to the manufacturer's instructions.

Primers which were designed for our previous studies (Farr et al., 2016) were used for RT-qPCR in this average of 2 reference genes (Actb and Tuba1) and the fold difference between the reference gene and the target gene [reference cycle threshold $(\mathrm{Ct})$ - gene of interest $\mathrm{Ct}$ ] was calculated by comparing the median $\mathrm{Ct}$ with NR-femurs serving as control for R-femurs, and young bone cells serving as controls for old.

\subsection{Statistical analysis} comparison of R and NR femurs (two-tailed). Individual animals were treated as indicated in the figure

417 legends. The R-based tool from Bioconductor, edgeR, was used to perform the differential expression analysis. Those mature mRNAs were significantly differentially expressed at a p-value $<0.05$ and a $\log 2$ 
fold change higher than 1 or less than -1 . Heat maps were created using Morpheus

420 software(https://software.broadinstitute.org/morpheus). For D+Q studies, statistical analyses were done

421 using GraphPad Prism and p values were calculated using a two-way ANOVA with a Dunnett's post hoc

422 test performed to compare vehicle- $\mathrm{R}$ with all the other groups. The $\mathrm{D}+\mathrm{Q}$ studies done in the aging cohort

423 were analyzed using a two-tailed unpaired t-test. Statistical comparisons of young, old, and radiated miRs

424 were done using one-way ANOVA with a Bonferroni post-hoc test.

\section{Acknowledgements}

427 This work was made possible by the Eagle's Cancer Research Fund (to AC), Mayo Clinic Clinical and 428 Translational Science Award (CTSA), grant number UL1TR002377, from the National Center for 429 Advancing Translational Science (NCATS), a component of the National Institutes of Health (NIH) (to 430 AC) and UL1TR000135, Center for Clinical and Translation Science (CCATS)(to DGM and AC), as well 431 as the Robert and Arlene Kogod Professorship (to RJP); P01 AG062413 (SK, JNF, RJP), P01 AG004875

432 (SK/DGM), R01 AG048792 (SK/DGM), R01 AR068275 (DGM), and, R01 DK128552 (JNF), and K01 433 AR070241 (JNF).

434 Author Contributions:

$435 \mathrm{AC}$ and RJP designed the study, $\mathrm{AC}, \mathrm{AL}, \mathrm{JNF}, \mathrm{MS}$ and $\mathrm{CH}$ performed the experiments, while $\mathrm{AC}, \mathrm{DM}$, 436 JNF, SK, JP and RJP analyzed and interpreted the data. AC and RJP wrote the manuscript and all authors 437 revised and approved the final version of the manuscript.

\section{References}


Almeida, M., Kim, H. N., Han, L., Zhou, D., Thostenson, J., Porter, R. M., ... Jilka, R. L. (2020). Increased marrow adipogenesis does not contribute to age-dependent appendicular bone loss in female mice. Aging Cell, 19(11), e13247. doi:10.1111/acel.13247

Ambele, M. A., Dessels, C., Durandt, C., \& Pepper, M. S. (2016). Genome-wide analysis of gene expression during adipogenesis in human adipose-derived stromal cells reveals novel patterns of gene expression during adipocyte differentiation. Stem Cell Res, 16(3), 725-734. doi:10.1016/j.scr.2016.04.011

Barneda, D., Frontini, A., Cinti, S., \& Christian, M. (2013). Dynamic changes in lipid droplet-associated proteins in the "browning" of white adipose tissues. Biochim Biophys Acta, 1831(5), 924-933. doi:10.1016/j.bbalip.2013.01.015

Birsoy, K., Berry, R., Wang, T., Ceyhan, O., Tavazoie, S., Friedman, J. M., \& Rodeheffer, M. S. (2011). Analysis of gene networks in white adipose tissue development reveals a role for ETS2 in adipogenesis. Development, 138(21), 4709-4719. doi:10.1242/dev.067710

Bou, M., Montfort, J., Le Cam, A., Ralliere, C., Lebret, V., Gabillard, J. C., . . Navarro, I. (2017). Gene expression profile during proliferation and differentiation of rainbow trout adipocyte precursor cells. BMC Genomics, 18(1), 347. doi:10.1186/s12864-017-3728-0

Bozaoglu, K., Bolton, K., McMillan, J., Zimmet, P., Jowett, J., Collier, G., . . Segal, D. (2007). Chemerin is a novel adipokine associated with obesity and metabolic syndrome. Endocrinology, 148(10), 46874694. doi:10.1210/en.2007-0175

Cao, J., Ding, K., Pan, G., Rosario, R., Su, Y., Bao, Y., . . Shi, X. (2020). Deletion of PPARgamma in Mesenchymal Lineage Cells Protects Against Aging-Induced Cortical Bone Loss in Mice. J Gerontol A Biol Sci Med Sci, 75(5), 826-834. doi:10.1093/gerona/glaa049

Cervellati, C., Bonaccorsi, G., Bergamini, C. M., Fila, E., Greco, P., Valacchi, G., .. Tisato, V. (2016). Association between circulatory levels of adipokines and bone mineral density in postmenopausal women. Menopause, 23(9), 984-992. doi:10.1097/GME.0000000000000655

Chandra, A., Lagnado, A. B., Farr, J. N., Monroe, D. G., Park, S., Hachfeld, C., . . Pignolo, R. J. (2020a). Targeted Reduction of Senescent Cell Burden Alleviates Focal Radiotherapy-Related Bone Loss. J Bone Miner Res, 35(6), 1119-1131. doi:10.1002/jbmr.3978

Chandra, A., Lagnado, A. B., Farr, J. N., Monroe, D. G., Park, S., Hachfeld, C., . . Pignolo, R. J. (2020b). Targeted Reduction of Senescent Cell Burden Alleviates Focal Radiotherapy-Related Bone Loss. J Bone Miner Res. doi:10.1002/jbmr.3978 
484

485

486

487

488

489

490

491

492

493

494

495

496

497

498

499

500

501

502

503

504

505

506

507

508

509

510

511

512

513

514

515

516

517

518

519

520

521

522

523

524

525

Chandra, A., Lin, T., Young, T., Tong, W., Ma, X., Tseng, W. J., .. . Qin, L. (2017). Suppression of Sclerostin Alleviates Radiation-Induced Bone Loss by Protecting Bone-Forming Cells and Their Progenitors Through Distinct Mechanisms. J Bone Miner Res, 32(2), 360-372. doi:10.1002/jbmr.2996

Chandra, A., Park, S. S., \& Pignolo, R. J. (2019). Potential role of senescence in radiation-induced damage of the aged skeleton. Bone, 120, 423-431. doi:10.1016/j.bone.2018.12.006

Chandra, A., Rosenzweig, A., \& Pignolo, R. J. (2018). Osteobiology of Aging. In R. J. Pignolo \& J. Ahn (Eds.), Fractures in the Elderly: A Guide to Practical Management (pp. 3-37). Cham: Springer International Publishing.

Chandra, A., Wang, L., Young, T., Zhong, L., Tseng, W. J., Levine, M. A., ... Qin, L. (2018). Proteasome inhibitor bortezomib is a novel therapeutic agent for focal radiation-induced osteoporosis. FASEB J, 32(1), 52-62. doi:10.1096/fj.201700375R

Coppe, J. P., Desprez, P. Y., Krtolica, A., \& Campisi, J. (2010). The senescence-associated secretory phenotype: the dark side of tumor suppression. Annu Rev Pathol, 5, 99-118.

doi:10.1146/annurev-pathol-121808-102144

Deng, K., Ren, C., Fan, Y., Liu, Z., Zhang, G., Zhang, Y., . . W Wang, F. (2020). miR-27a is an important adipogenesis regulator associated with differential lipid accumulation between intramuscular and subcutaneous adipose tissues of sheep. Domest Anim Endocrinol, 71, 106393. doi:10.1016/j.domaniend.2019.106393

Devlin, M. J., \& Rosen, C. J. (2015). The bone-fat interface: basic and clinical implications of marrow adiposity. Lancet Diabetes Endocrinol, 3(2), 141-147. doi:10.1016/S2213-8587(14)70007-5

Dobin, A., Davis, C. A., Schlesinger, F., Drenkow, J., Zaleski, C., Jha, S., ... Gingeras, T. R. (2013). STAR: ultrafast universal RNA-seq aligner. Bioinformatics, 29(1), 15-21. doi:10.1093/bioinformatics/bts635

Farr, J. N., Fraser, D. G., Wang, H., Jaehn, K., Ogrodnik, M. B., Weivoda, M. M., . . Khosla, S. (2016). Identification of Senescent Cells in the Bone Microenvironment. J Bone Miner Res, 31(11), 19201929. doi:10.1002/jbmr.2892

Farr, J. N., Xu, M., Weivoda, M. M., Monroe, D. G., Fraser, D. G., Onken, J. L., . . Khosla, S. (2017). Targeting cellular senescence prevents age-related bone loss in mice. Nat Med, 23(9), 10721079. doi:10.1038/nm.4385

Goralski, K. B., McCarthy, T. C., Hanniman, E. A., Zabel, B. A., Butcher, E. C., Parlee, S. D., . . Sinal, C. J. (2007). Chemerin, a novel adipokine that regulates adipogenesis and adipocyte metabolism. $J$ Biol Chem, 282(38), 28175-28188. doi:10.1074/jbc.M700793200 
Hackl, M., Brunner, S., Fortschegger, K., Schreiner, C., Micutkova, L., Muck, C., . . Grillari, J. (2010). miR17, miR-19b, miR-20a, and miR-106a are down-regulated in human aging. Aging Cell, 9(2), 291296. doi:10.1111/j.1474-9726.2010.00549.x

Hayflick, L. (1965). THE LIMITED IN VITRO LIFETIME OF HUMAN DIPLOID CELL STRAINS. Exp Cell Res, 37, 614-636.

Hotta, K., Funahashi, T., Matsukawa, Y., Takahashi, M., Nishizawa, H., Kishida, K., . . Matsuzawa, Y. (2001). Galectin-12, an Adipose-expressed Galectin-like Molecule Possessing Apoptosis-inducing Activity. J Biol Chem, 276(36), 34089-34097. doi:10.1074/jbc.M105097200

Inoue, N., Yahagi, N., Yamamoto, T., Ishikawa, M., Watanabe, K., Matsuzaka, T., ... Shimano, H. (2008). Cyclin-dependent kinase inhibitor, p21WAF1/CIP1, is involved in adipocyte differentiation and hypertrophy, linking to obesity, and insulin resistance. J Biol Chem, 283(30), 21220-21229. doi:10.1074/jbc.M801824200

Ivanovska, I., Ball, A. S., Diaz, R. L., Magnus, J. F., Kibukawa, M., Schelter, J. M., . . Cleary, M. A. (2008). MicroRNAs in the miR-106b family regulate $\mathrm{p} 21 / \mathrm{CDKN1A}$ and promote cell cycle progression. Mol Cell Biol, 28(7), 2167-2174. doi:10.1128/MCB.01977-07

Kalari, K. R., Nair, A. A., Bhavsar, J. D., O'Brien, D. R., Davila, J. I., Bockol, M. A., . . Kocher, J. P. (2014). MAP-RSeq: Mayo Analysis Pipeline for RNA sequencing. BMC Bioinformatics, 15, 224. doi:10.1186/1471-2105-15-224

Kobayashi, S., Fukuhara, A., Taguchi, T., Matsuda, M., Tochino, Y., Otsuki, M., \& Shimomura, I. (2010). Identification of a new secretory factor, CCDC3/Favine, in adipocytes and endothelial cells. Biochem Biophys Res Commun, 392(1), 29-35. doi:10.1016/j.bbrc.2009.12.142

Kogame, M., Matsuo, S., Nakatani, M., Kurisaki, A., Nishitani, H., Tsuchida, K., \& Sugino, H. (2006). ALK7 is a novel marker for adipocyte differentiation. J Med Invest, 53(3-4), 238-245. doi:10.2152/jmi.53.238

Kusuyama, J., Komorizono, A., Bandow, K., Ohnishi, T., \& Matsuguchi, T. (2016). CXCL3 positively regulates adipogenic differentiation. J Lipid Res, 57(10), 1806-1820. doi:10.1194/jlr.M067207

Liao, Y., Smyth, G. K., \& Shi, W. (2013). The Subread aligner: fast, accurate and scalable read mapping by seed-and-vote. Nucleic Acids Res, 41(10), e108. doi:10.1093/nar/gkt214

Lin, Q., Gao, Z., Alarcon, R. M., Ye, J., \& Yun, Z. (2009). A role of miR-27 in the regulation of adipogenesis. FEBS J, 276(8), 2348-2358. doi:10.1111/j.1742-4658.2009.06967.x 
568

569

570

571

572

573

574

575

576

577

578

579

580

581

582

583

584

585

586

587

588

589

590

591

592

593

594

595

596

597

598

599

600

601

602

603

604

605

606

607

608

609

Love, M. I., Huber, W., \& Anders, S. (2014). Moderated estimation of fold change and dispersion for RNA-seq data with DESeq2. Genome Biol, 15(12), 550. doi:10.1186/s13059-014-0550-8

MacDougald, O. A., \& Burant, C. F. (2007). The rapidly expanding family of adipokines. Cell Metab, 6(3), 159-161. doi:10.1016/j.cmet.2007.08.010

McKenna, A., Hanna, M., Banks, E., Sivachenko, A., Cibulskis, K., Kernytsky, A., . . DePristo, M. A. (2010). The Genome Analysis Toolkit: a MapReduce framework for analyzing next-generation DNA sequencing data. Genome Res, 20(9), 1297-1303. doi:10.1101/gr.107524.110

Menssen, A., Haupl, T., Sittinger, M., Delorme, B., Charbord, P., \& Ringe, J. (2011). Differential gene expression profiling of human bone marrow-derived mesenchymal stem cells during adipogenic development. BMC Genomics, 12, 461. doi:10.1186/1471-2164-12-461

Milisic, L., Vegar-Zubovic, S., \& Valjevac, A. (2020). Bone marrow adiposity is inversely associated with bone mineral density in postmenopausal females. Med Glas (Zenica), 17(1). doi:10.17392/105320

Muruganandan, S., Dranse, H. J., Rourke, J. L., McMullen, N. M., \& Sinal, C. J. (2013). Chemerin neutralization blocks hematopoietic stem cell osteoclastogenesis. Stem Cells, 31(10), 2172-2182. doi:10.1002/stem.1450

Ortega, F. J., Vazquez-Martin, A., Moreno-Navarrete, J. M., Bassols, J., Rodriguez-Hermosa, J., Girones, J., ... Fernandez-Real, J. M. (2010). Thyroid hormone responsive Spot 14 increases during differentiation of human adipocytes and its expression is down-regulated in obese subjects. Int $J$ Obes (Lond), 34(3), 487-499. doi:10.1038/ijo.2009.263

Ralston, J. C., \& Mutch, D. M. (2015). SCD1 inhibition during 3T3-L1 adipocyte differentiation remodels triacylglycerol, diacylglycerol and phospholipid fatty acid composition. Prostaglandins Leukot Essent Fatty Acids, 98, 29-37. doi:10.1016/j.plefa.2015.04.008

Scheideler, M., Elabd, C., Zaragosi, L. E., Chiellini, C., Hackl, H., Sanchez-Cabo, F., . . Trajanoski, Z. (2008). Comparative transcriptomics of human multipotent stem cells during adipogenesis and osteoblastogenesis. BMC Genomics, 9, 340. doi:10.1186/1471-2164-9-340

Secco, B., Camire, E., Briere, M. A., Caron, A., Billong, A., Gelinas, Y., . . Laplante, M. (2017). Amplification of Adipogenic Commitment by VSTM2A. Cell Rep, 18(1), 93-106. doi:10.1016/j.celrep.2016.12.015

Singh, L., Brennan, T. A., Russell, E., Kim, J. H., Chen, Q., Brad Johnson, F., \& Pignolo, R. J. (2016). Aging alters bone-fat reciprocity by shifting in vivo mesenchymal precursor cell fate towards an adipogenic lineage. Bone, 85, 29-36. doi:10.1016/j.bone.2016.01.014 
610

611

612

613

614

615

616

617

618

619

620

621

622

623

624

625

626

627

628

629

630

631

632

633

634

635

636

637

638

639

640

641

642

643

644

645

646

647

648

649

650

651

652

Suchacki, K. J., \& Cawthorn, W. P. (2018). Molecular Interaction of Bone Marrow Adipose Tissue with Energy Metabolism. Curr Mol Biol Rep, 4(2), 41-49. doi:10.1007/s40610-018-0096-8

Terzoudis, S., Malliaraki, N., Damilakis, J., Dimitriadou, D. A., Zavos, C., \& Koutroubakis, I. E. (2016). Chemerin, visfatin, and vaspin serum levels in relation to bone mineral density in patients with inflammatory bowel disease. Eur J Gastroenterol Hepatol, 28(7), 814-819. doi:10.1097/MEG.0000000000000617

Turaga, R. V., Paquet, E. R., Sild, M., Vignard, J., Garand, C., Johnson, F. B., . . Lebel, M. (2009). The Werner syndrome protein affects the expression of genes involved in adipogenesis and inflammation in addition to cell cycle and DNA damage responses. Cell Cycle, 8(13), 2080-2092. doi:10.4161/cc.8.13.8925

Veldhuis-Vlug, A. G., \& Rosen, C. J. (2018). Clinical implications of bone marrow adiposity. J Intern Med, 283(2), 121-139. doi:10.1111/joim.12718

Wang, C., Davila, J. I., Baheti, S., Bhagwate, A. V., Wang, X., Kocher, J. P., . . Asmann, Y. W. (2014). RVboost: RNA-seq variants prioritization using a boosting method. Bioinformatics, 30(23), 34143416. doi:10.1093/bioinformatics/btu577

Wang, C., Li, X., Dang, H., Liu, P., Zhang, B. O., \& Xu, F. (2019). Insulin-like growth factor 2 regulates the proliferation and differentiation of rat adipose-derived stromal cells via IGF-1R and IR. Cytotherapy, 21(6), 619-630. doi:10.1016/j.jcyt.2018.11.010

Wang, L., Wang, S., \& Li, W. (2012). RSeQC: quality control of RNA-seq experiments. Bioinformatics, 28(16), 2184-2185. doi:10.1093/bioinformatics/bts356

Woods, G. N., Ewing, S. K., Sigurdsson, S., Kado, D. M., Eiriksdottir, G., Gudnason, V., . . Schwartz, A. V. (2020). Greater Bone Marrow Adiposity Predicts Bone Loss in Older Women. J Bone Miner Res, 35(2), 326-332. doi:10.1002/jbmr.3895

Yin, C., Xiao, Y., Zhang, W., Xu, E., Liu, W., Yi, X., \& Chang, M. (2014). DNA microarray analysis of genes differentially expressed in adipocyte differentiation. J Biosci, 39(3), 415-423.

doi:10.1007/s12038-014-9412-5

Yu, Y., Du, H., Wei, S., Feng, L., Li, J., Yao, F., . . Chen, L. (2018). Adipocyte-Derived Exosomal MiR-27a Induces Insulin Resistance in Skeletal Muscle Through Repression of PPARgamma. Theranostics, 8(8), 2171-2188. doi:10.7150/thno.22565

Zhong, L., Yao, L., Tower, R. J., Wei, Y., Miao, Z., Park, J., . . Q Qin, L. (2020). Single cell transcriptomics identifies a unique adipose lineage cell population that regulates bone marrow environment. Elife, 9. doi:10.7554/eLife.54695 
bioRxiv preprint doi: https://doi.org/10.1101/2021.09.07.459232; this version posted September 8, 2021. The copyright holder for this preprint (which was not certified by peer review) is the author/funder, who has granted bioRxiv a license to display the preprint in perpetuity. It is made available under aCC-BY 4.0 International license.

653

654

655

656

657

658
Zou, W., Rohatgi, N., Brestoff, J. R., Li, Y., Barve, R. A., Tycksen, E., . . Teitelbaum, S. L. (2020). Ablation of Fat Cells in Adult Mice Induces Massive Bone Gain. Cell Metab, 32(5), 801-813 e806. doi:10.1016/j.cmet.2020.09.011
A

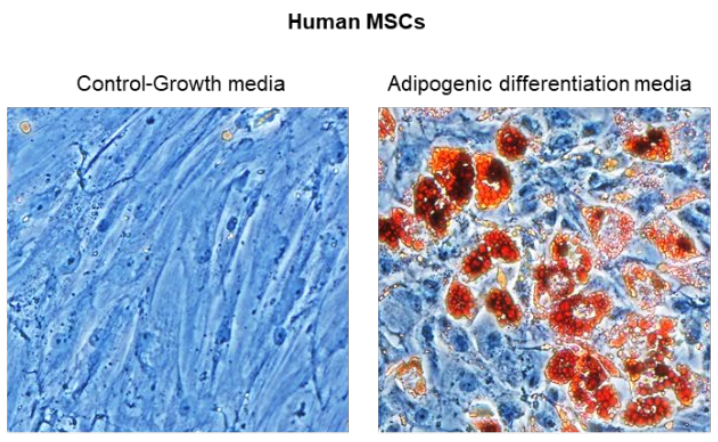

B

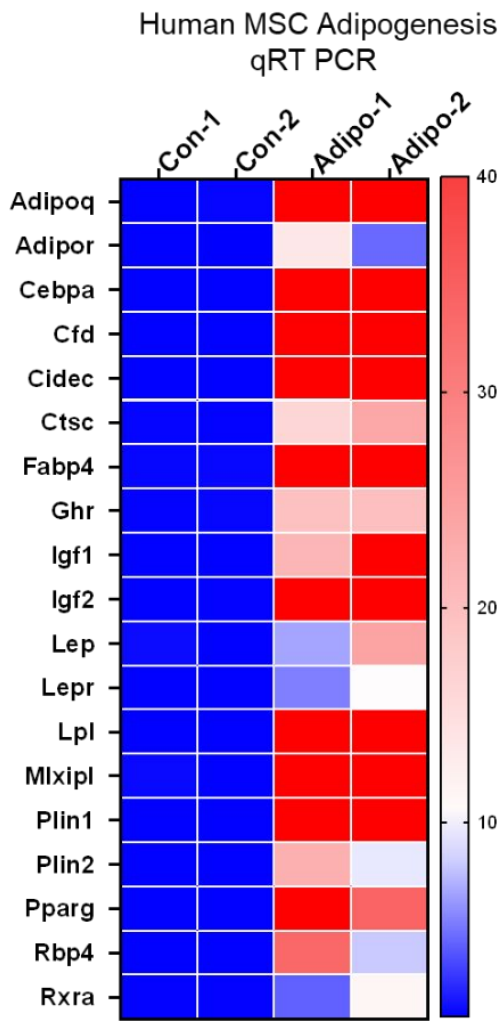

Supplementary Figure1. The genes which were linked by a STRING network, and selected for further validation in vivo, were validated by qRT-PCR in an adipocyte differentiation assay in human MSCs. mRNA from control and differentiated adipocytes were analyzed 2 weeks post-differentiation. The fold changes are shown as a heat map with fold changes above 40 represented as red. 
bioRxiv preprint doi: https://doi.org/10.1101/2021.09.07.459232; this version posted September 8, 2021. The copyright holder for this preprint (which was not certified by peer review) is the author/funder, who has granted bioRxiv a license to display the preprint in perpetuity. It is made available under aCC-BY 4.0 International license.

A

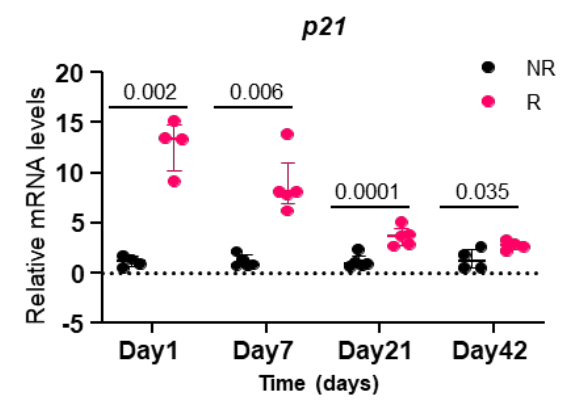

p16 $^{\text {INK4a }}$

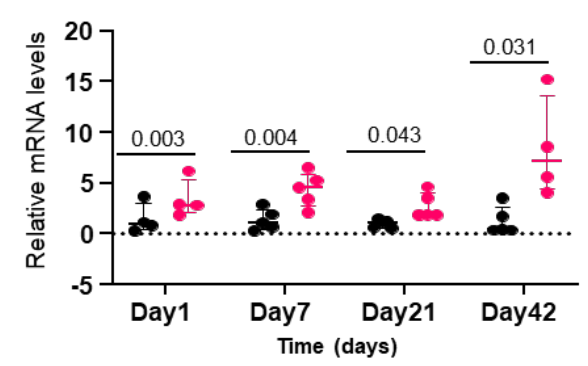

B
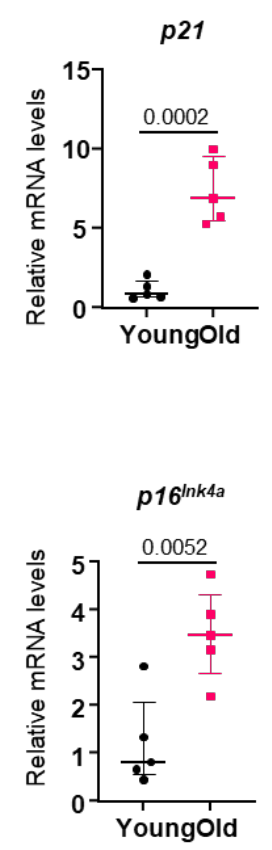

Supplementary Figure 2. Comparative analysis of senescence markers in radiated and aged bones

Longitudinal assessments of senescence markers $C d k n 1 a(p 21)$ and $C d k n 2 a\left(p 16^{\operatorname{lnk} k a}\right)$ in R- and aged-bones. (A) The right femoral metaphyses of C57BL/6 mice were radiated (24Gy) in a $5 \mathrm{~mm}$ region, while the equivalent region of the left leg served as control. On days $1(n=4), 7(n=5), 21(n=5)$ and $42(n=4) R$ - and NR-femurs were harvested for mRNA isolation. Statistical analyses were done using GraphPad Prism and p-values were calculated using a two-tailed paired t-test. (B) Whole bones were collected from young $(5 \mathrm{~m})(\mathrm{n}=5)$ and old $(24 \mathrm{~m})(\mathrm{n}=5)$ mice and mRNA were isolated. Results are expressed as medians with interquartile range. Statistical analyses were done using GraphPad Prism and p-values were calculated using a two-tailed unpaired t-test. 
668 Supplementary Table S1. Mouse primer sequences

\begin{tabular}{|l|l|l|}
\hline Gene & Forward Primer sequence (5'-3') & Reverse Primer Sequence (5'-3') \\
\hline Actb & AATCGTGCGTGACATCAAAGAG & GCCATCTCCTGCTCGAAGTC \\
\hline Adipoq & AAAGGAGAGCCTGGAGAAGC & CGAATGGGTACATTGGGAAC \\
\hline Cfd & TGTCAATCATGAACCGGACAA & GGTGACTACCCCGTCATGGT \\
\hline Cidec & CCATCAGAACAGCGCAAGAA & TAGAGGGTTGCCTTCACGTT \\
\hline Ctsc & TGCAGCACATCTTGGAGGTCTC & GCAGTCCAAGACTTCTGAACGG \\
\hline Fabp4 & GAATGTGTTATGAAAGGCGTGAC & AAATTTCCATCCAGGCCTCT \\
\hline Fabp5 & GATGGCAACAACATCACGGT & GGTGCAGACCGTCTCAGTTT \\
\hline Ghr & GCAACCTGATCCACCCATTG & AGGGCCCATCACTTTCCATT \\
\hline lgf1 & AAAAGCAGCCCGCTCTATCC & CTTCTGAGTCTTGGGCATGTCA \\
\hline lgf2 & CATCGTCCCCTGATCGTGTTA & TTGCTGGACATCTCCGAAGAG \\
\hline Lep & ACATTTCACACACGCAGTCG & GCCCAGGAATGAAGTCCAAG \\
\hline Lepr & GTCACCTCTGATGTCACTGC & CCATTGTTTGGCTGTCCCAA \\
\hline Mlxipl & TTACAGTGGCAAGCTGGTCT & CTCCAGATGGCGTTGTTCAG \\
\hline Plin1 & TGGACCACCTGGAGGAAAAG & TTCGAAGGCGGGTAGAGATG \\
\hline Plin2 & CTCAGGAGGAGCTGGAGATG & CGAGAGCAGAGCTTGGTAGA \\
\hline Plin4 & GGAGACAAGGACATGGGAAGTT & TGCCAAACACCCCAGAGAAG \\
\hline Rarres2 & AGGAGTTCCACAAACACCCA & CAAAGGTGCCAGCTGAGAAG \\
\hline Rbp4 & TCTGAGCAACTGGGAAGTGT & CGTTTCCTCGCTGGAGAAAG \\
\hline Rxra & AGCTCACCAAATGACCCTGT & AAGTGTGGGATCCTCTTGGC \\
\hline Tuba1 & GGTTCCCAAAGATGTCAATGCT & CAAACTGGATGGTACGCTTGGT \\
\hline
\end{tabular}

669

670

671

672

673

674

675

676

677

678 
679 Supplementary Table S2. Human primer sequences

\begin{tabular}{|l|l|l|}
\hline & Forward Primer sequence (5'-3') & Reverse Primer Sequence (5'-3') \\
\hline Actb & CCCAGCCATGTACGTTGCTAT & TCACCGGAGTCCATCACGAT \\
\hline Adipoq & GCTCTGTGCTCCTGCATCTG & ACGCTCTCCTTCCCCATACA \\
\hline Adipor & TGGCAAATGTGACATCTGGTTT & AAGCTCCAGCAACCACAAAGA \\
\hline Cebpa & ACCTTGTGCCTTGGAAATGC & CGATTTGCTCCCCCTACTCA \\
\hline Cfd & GCTACAGCTGTCGGAGAAGG & CAGCACTGGCAAGAGCAC \\
\hline Cidec & CTGGCAGGGGATACAGTGTT & GTCCTGTGGGTTCAGCTTGT \\
\hline Ctsc & TGCCAACTGCACCTATCTTG & CAGAATTGCCAAGGTCATCA \\
\hline Fabp4 & GCAGAAATGGGATGGAAAATCA & ACGCATTCCACCACCAGTTTA \\
\hline Ghr & AAATTCACCAAGTGCCGTTC & TCAGGGCATTCTTTCCATTC \\
\hline Igf1 & TCCGGAGCTGTGATCTAAGG & CCTGCACTCCCTCTACTTGC \\
\hline Igf2 & CAGACCCCCAAATTATCGTG & AGAAGCACCAGCATCGACTT \\
\hline Lep & GGCTTTGGCCCTATCTTTTC & CCCCTCACCTGAACCTCATA \\
\hline Lepr & GTGAAGCCTGATCCACCATT & CCCCTCACCTGAACCTCATA \\
\hline Mlxipl & GGAGGGGAACTACTGGAAGC & GGACCACACTGGAGAAGAGC \\
\hline Plin1 & TCTCTCGATACACCGTGCAG & TGGTCCTCATGATCCTCCTC \\
\hline Plin2 & CCTTGGTGAGCTCCACGTAT & CAATTTGCGGCTCTAGCTTC \\
\hline Pparg & CGGAACACGTGCAGCTACTG & GAGCGGGTGAAGACTCATGTCT \\
\hline Rbp4 & GCCTCTTTCTGCAGGACAAC & CACGGCATACGTGTCGTAGT \\
\hline Rxra & CCTTTCTCGGTCATCAGCTC & CTTGGTGAAGGAAGCCATGT \\
\hline Tuba1 & GAGTGCATCTCCATCCACGTT & TAGAGCTCCCAGCAGGCATT \\
\hline
\end{tabular}

